\title{
CFD-BASED DESIGN OPTIMIZATION FOR SINGLE ELEMENT ROCKET INJECTOR
}

\author{
Rajkumar Vaidyanathan ${ }^{(1)^{*}}$, Kevin Tucker ${ }^{(2) \dagger}$, Nilay Papila ${ }^{(1) \dagger}$ and Wei Shyy ${ }^{(1) \ddagger}$ \\ ${ }^{(1)}$ Department of Mechanical and Aerospace Engineering \\ University of Florida, Gainesville, FL 32611. \\ ${ }^{(2)}$ NASA Marshall Space Flight Center \\ MS/TD64, MSFC, AL 35812
}

\begin{abstract}
To develop future Reusable Launch Vehicle concepts, we have conducted design optimization for a single element rocket injector, with overall goals of improving reliability and performance while reducing cost. Computational solutions based on the Navier-Stokes equations, finite rate chemistry, and the $k-\varepsilon$ turbulence closure are generated with design of experiment techniques, and the response surface method is employed as the optimization tool. The design considerations are guided by four design objectives motivated by the consideration in both performance and life, namely, the maximum temperature on the oxidizer post tip, the maximum temperature on the injector face, the adiabatic wall temperature, and the length of the combustion zone. Four design variables are selected, namely, $\mathrm{H}_{2}$ flow angle, $\mathrm{H}_{2}$ and $\mathrm{O}_{2}$ flow areas with fixed flow rates, and $\mathrm{O}_{2}$ post tip thickness. In addition to establishing optimum designs by varying emphasis on the individual objectives, better insight into the interplay between design variables and their impact on the design objectives is gained. The investigation indicates that improvement in performance or life comes at the cost of the other. Best compromise is obtained when improvements in both performance and life are given equal importance.
\end{abstract}

* Graduate Student Assistant, Student Member AIAA

$\dagger$ Aerospace Engineer, Member AIAA

$¥$ Professor and Dept. Chair, Fellow AIAA

Copyright $@ 2003$ by the American Institute of Aeronautics and Astronautics, Inc. All rights reserved.

\section{INTRODUCTION}

The Space Shuttle has been propelled into space for the last 20 years by the world's most sophisticated reusable engine, the Space Shuttle Main Engine (SSME). However, due to limited knowledge base and stringent operating conditions, the engine's key hot-section components, including combustion devices and turbomachinery, have encountered reliability issues. Consequently, frequent maintenance and periodic redesign have been required, resulting in high operation costs. The goal of NASA's Next Generation Launch Technology (NGLT) program is to develop technologies to make the next generation launch systems safer, more affordable and more reliable. Design of robust combustion devices, namely, injectors, chambers and nozzles, is an important element in meeting these ambitious goals.

Thrust chamber is an important part of a liquid propellant rocket engine. It takes in the propellants through the injector, atomizes, vaporizes, mixes and burns it in the combustion chamber and accelerates the produced gases, which are then ejected out to produce the required thrust. Hence, the performance and the environment influencing it are, to a large extent, governed by the design of the injector. The performance is determined by the rate and the extent to which the propellants mix and resultant combustion occurs. This mixing efficiency is a function of the details of the injector design. On the other hand, the location of the mixing and combustion is a key in determining the thrust chamber thermal environment. This environment directly affects the component life, including temperatures on the combustor wall, injector face and, for coaxial injectors, the oxidizer post tip. The difficulty encountered in designing injectors that perform well and have manageable environment is that, generally, the factors that promote performance also lead to increased heat fluxes to the solid surfaces in the combustor.

Current injector design tools have been in use for 30 years or more ${ }^{1-5}$, and are largely empirical-based. The experimental databases, and thus the tools developed from them, are limited, in terms of design space, to specific element configurations that have been tested ${ }^{6}$. In terms of scope, the design tools typically focus on performance with the environment, being a secondary consideration. The limited amount of environmental information available from these tools is usually sketchy and not calculated as a function of the details of the injector design. It is very doubtful that application of these traditional design tools will result in future propulsion devices that meet the goals noted above.

With rapid progress made in computational fluid dynamics (CFD), we can now develop improved design tools for rocket propulsion. However, there are three requirements that the CFD tool must meet before it can be routinely employed in the design process. First, there must be an increased fidelity of the solution over the historical tools in terms of numerical accuracy and physical modeling. Second, a rigorous validation process is required before the designer can confidently 
employ CFD as a tool for quantitative decision-making. Finally, a significant quantity of parametric solutions must be obtainable during the design cycle time frame.

The application of CFD to injector design has lagged behind other areas such as turbomachinery because the physical problems are more complicated for multiphase, turbulent reacting flows. Although many challenges remain, it is our view that with concerted community efforts, significant gain in applying computational tools for the design of injector and other combustion devices can be realized in the near future. For example, new models that efficiently account for some of the complex processes ${ }^{7}$ and, thus, increase the solution fidelity, have recently become available. The three-dimensional geometry of multi-element injectors and the complex physical processes inherent in the flows that issue from them create major problems in the other two areas in terms of using CFD as a design tool. The harsh high pressure and temperature environments typical of injector flows create significant difficulty in obtaining experimental data of satisfactory quality to validate and guide further development of computational models. Additionally, solving the equations, for multiphase reacting flows, with high resolution typically requires long computational time. However, the continued increase in computer speed and progress in parallel processing has begun to soften this turnaround problem.

It has long been known that small changes in injector geometry can have significant impact on performance ${ }^{8}$, as well as on environmental variables such as combustion chamber wall and injector face temperatures and heat fluxes. CFD can be fruitfully used to account for several independent geometrical variables over appropriate ranges to assess the impact on design goals. To effectively accomplish this multi-objective exercise, an optimization technique is desirable to assist and guide the designer in objective management of the complex and competing trends embodied in the CFD-generated data.

\section{SCOPE \& APPROACH}

In the present effort, a CFD-based injector design/optimization methodology for single element injectors is proposed and applied to an injector targeted for the future reusable launch vehicle technologies. While the ultimate goal is to analyze multi-element injectors, much of the detailed work in injector design can be done, or at least initiated, at the single element level. In the present effort, the focus is on the single element methodology. CFD solutions based on the Navier-Stokes equations, finite rate chemistry, and the $k-\varepsilon$ turbulence closure are generated with design of experiment (DOE) techniques $^{9,10}$, and the response surface (RS) method $^{9}$ is employed as the optimization tool. The design considerations are guided by four design objectives, namely, the maximum temperature on the oxidizer post tip, the maximum temperature on the injector face, the adiabatic wall temperature, and the length of the combustion zone. Together, they address the concerns arising from injector performance and life. Four design variables are selected, namely, $\mathrm{H}_{2}$ flow angle, $\mathrm{H}_{2}$ and $\mathrm{O}_{2}$ flow areas with fixed mass flow rates in fuel and oxidizer, and $\mathrm{O}_{2}$ post tip thickness. As a proof of the concept, the present CFD-RS optimization strategy is demonstrated in the context of a coaxial element using gaseous oxygen $\left(\mathrm{GO}_{2}\right)$ and gaseous hydrogen $\left(\mathrm{GH}_{2}\right)$ propellants. The response surface generation is evaluated for two grids of different resolutions and the relationship between the optimization process and CFD solution process is explored. Finally, the response surfaces are used in three separate optimization examples demonstrating the utility and flexibility of the methodology.

To facilitate the development of the present methodology, a baseline element design is needed as a starting point. This baseline concept is generated by an empirical design methodology based on a specific set of propellant flow rates, mixture ratio and chamber pressure. Dependent variables to characterize performance and environments can then be estimated from this design. The selected design variables are then varied based on this baseline design and the design space populated with the aid of DOE technique. The CFD cases are run and post processed to extract the required dependent variable data. This data is then used to generate a response surface for each dependent variable in terms of the independent variables, and an optimization technique is applied to identify suitable designs. Details on these ideas/processes will be provided after describing the injector model.

\section{Injector Model}

In liquid rocket propulsion, there are two basic types of injector elements. The first type is an impinging element (Figure 1a) where mixing occurs by direct impingement of the propellant streams at an acute angle. The impingement enhances mixing by head-on interaction between the oxidizer and fuel ${ }^{8}$. The second type of injector consists of nonimpinging elements where the propellant streams flow in parallel, typically in coaxial fashion (Figure 1b). Here, mixing is enhanced through shear-mixing processes"

From a design standpoint, both element types have some appealing characteristics. For instance, if the impinging element has an F-O-F arrangement, the mixing occurs rapidly, which can yield high performance. However, since the combustion zone is close to the injector face, the potential for high levels of injector face heating must be addressed. If the non-impinging element is assumed to be a shear coaxial element, mixing across the shear layer is relatively slow ${ }^{8}$, requiring longer chambers to allow complete combustion. Since the combustion zone is spread over a longer axial distance, the injector face is generally exposed to less severe thermal environments. Important parameters for the impinging element 
(assuming fixed mass flow rates and constant propellant inlet conditions) include relative orifice size (or, relative stream momentum ratio), impingement angle and orifice spacing. Important parameters for the shear coaxial element (assuming fixed mass flow rates and constant propellant inlet conditions) include the area ratio of the two concentric tubes (or velocity ratio) and the shear area between the two propellant streams (the oxidizer post tip thickness) ${ }^{11}$.

Of course, one can combine the above-mentioned characteristics of injector types to develop hybrid concepts. For example, it has been noted ${ }^{8}$ that modifications for performance improvement in the shear coaxial element can be realized by directing the fuel toward the oxidizer stream rather than parallel to it and thinning the oxidizer post wall. Both modifications allow the shear coaxial element to take on some of the aspects of the F-O-F impinging element. These notions lead to the hybrid element shown in Figure 2 that has been developed by The Boeing Company (U. S. Patent 6253539).

Four independent design variables are chosen for the element shown in Figure 3a, namely, the angle at which the $\mathrm{H}_{2}$ is directed toward the oxidizer, Variable-1 $(\alpha)$, the change in $\mathrm{H}_{2}$ flow area from the baseline, Variable-2 $(\Delta \mathrm{HA})$, the change in $\mathrm{O}_{2}$ flow area from the baseline, Variable-3 $(\Delta \mathrm{OA})$, and the oxidizer post tip thickness, Variable-4 (OPTT). The fuel and oxidizer flow rates are held unchanged. The ranges of the independent variables are shown in Table 1 . The dependent variables chosen are the maximum face temperature, Objective- $1\left(\mathrm{TF}_{\mathrm{max}}\right)$, the wall temperature at a distance three inches from the injector face, Objective-2 $\left(\mathrm{TW}_{4}\right)$, the maximum oxidizer post tip temperature, Objective- $3\left(\mathrm{TT}_{\max }\right)$ and centerline axial location where the combustion is $99 \%$ complete, Objective- 4 (hereafter referred to as the combustion length, $X_{c i}$ ) (Figure $3 b)$. The combustion length, Objective- $4\left(\mathrm{X}_{\mathrm{cc}}\right)$, was chosen as a measure of performance. Shorter combustion lengths indicate better performing designs. The three temperatures (calculated as adiabatic wall temperatures in this study) were chosen as indicators of local environments. Lower temperatures would indicate a design that had longer life due to decreased thermal strain on the part.

\section{Numerical Procedure}

A pressure-based, finite difference, Navier-Stokes solver, FDNS500-CVS ${ }^{12-14}$, is used in this study. The Navier-Stokes equations, the two-equation turbulence model, and kinetic equations are solved. Convection terms are discretized using either a second order upwind, third order upwind or a central difference scheme, with adaptively added second order and fourth order dissipation terms. For the viscous and source terms, second order central differencing scheme is used. First order upwind scheme is used for scalar quantities like turbulence kinetic energy and species mass fractions, so as to ensure positive values. Steady state is assumed and an implicit Euler time marching scheme is used for computational efficiency. The chemical species continuity equations represent the $\mathrm{H}_{2}-\mathrm{O}_{2}$ chemistry. It is represented with the aid of a 7-species and 9-reaction set ${ }^{12-14}$. The simulation domain and the boundary conditions used in all the CFD cases are shown in Figure 4. Because of the very large aspect ratio, both the injector and chamber have been shortened (at the cross hatched areas) for clarity. Both fuel and oxidizer flow in through the west boundary where the mass flow rate is fixed for both streams. The nozzle exit, at the east boundary, is modeled by an outlet boundary condition. The south boundary is modeled with the symmetry condition. All walls (both sides of the oxygen post, the outside of the fuel annulus, the outside chamber wall, and the faceplate) are modeled with the no slip adiabatic wall boundary condition.

\section{Design of Experiments}

The predictive capability of a response surface (RS) is largely dependent on the selection of the design space as it dictates the distribution of the available information. There are different types of design of experiments (DOE) techniques. Among various alternatives, the orthogonal array $(O A)^{15}$, which is an efficient approach, is used here. An OA is a fractional factorial matrix that assures a balanced comparison of levels of any factor or interaction of factors ${ }^{15}$. Consider $\boldsymbol{A}$, a matrix with elements of $a_{i}^{j}$ where $j$ shows the row $\left(j=1,2 \ldots n_{r}\right)$ and $i$ shows the column $\left(i=1,2 \ldots n_{c}\right)$ that $a_{i}^{j}$ belongs to, supposing that each $a_{i}^{j} \in Q=\{0,1 \ldots q-1\}$. A is called an orthogonal array of strength $t \leq n_{c}$ if in each $n_{r}$-row-by-t-column sub-matrix of all $q^{\prime}$ possible distinct rows occur $\lambda$ times. Such an array is denoted by $O A\left(n_{n} n_{c}, q, t\right)$ by Owen ${ }^{15}$. Based on the DOE theory, orthogonal arrays can significantly reduce the number of experimental configurations. Information directly relevant to the use of OA can be found in the works of Shyy et al. ${ }^{16}$ and Papila ${ }^{17}$.

In the present study, using OA 54 designs are generated for fitting and testing the response surface. To test the RS, 14 of the 54 designs are selected using cross-validation techniques. Cross-validation ${ }^{17}$ is an established technique for estimating the prediction accuracy. This method is usually performed using either a number of random test/train partitions of the data, or $k$-fold cross-validation ${ }^{18}$. During the CFD computations, 2 of the 40 designs (training set) were found to be unacceptable because they exhibited unsteady behaviors while the numerical algorithm was based on the steady state model. Hence the final information included 38 designs for training the RS and 14 to test their predictive capabilities. All the design variables are normalized between 0 and 1 based on their maximum and minimum values. All the responses obtained from the CFD solutions of the 52 valid designs are scaled to $O(1)$ and RS generated. Once the RS are generated, the responses are renormalized between 0 and 1 based on the maximum and minimum of the generated RS, which will be referred to as the normalized responses in the text. Henceforth these normalized values will be used in this paper. The 
training and testing designs are shown in Table $\mathrm{Al}$ in the appendix. It should be noted that when the Variable-3 $(\triangle \mathrm{OA})$ is 1 or 0 , the $\mathrm{O}_{2}$ flow area is reduced by $0 \%$ or $40 \%$, respectively, as compared to the baseline area.

\section{Response Surface Methodology}

The response surface methodology (RSM) is adopted in the present study. This technique is effective in representing the global characteristics of the design space and it filters noise associated with design data. However, depending on the order of polynomial employed and the shape of the actual response surface, the RSM can introduce substantial errors due to its generally low order representation. However, the number of design points needed to construct a response surface increases rapidly with the number of design variables. For example, for a second order response surface, the number of coefficients associated with the polynomial scales with the number of design variables, $N$, as $(N+1)(N+2) /(2 !)$, while a third order polynomial scales as $(N+1)(N+2)(N+3) /(3 !)$.

In this study the response surfaces are fit with $\mathrm{n}^{\text {th }}$ order polynomials using standard least-squares regression. Statistical analysis software, $\mathrm{JMP}^{19}$, is used for the generation of the polynomials. In the standard least-squares regression method, based on t-statistics', terms with least influence in the prediction are discarded and the prediction improved, which gives the reduced model. The quality of fit between different surfaces can be evaluated by comparing the adjusted RMS error ${ }^{9}, \sigma_{\mathrm{a}}$, defined as:

$\sigma_{a}=\sqrt{\frac{\sum \varepsilon_{i}^{2}}{n-p}}$

where $\varepsilon_{i}$ is the error at the $i^{t h}$ point, $n$ is the number of data points and $p$ is the number of coefficients. The measure of error given by $\sigma_{\mathrm{a}}$ is normalized to account for the degrees of freedom in the model. This adjusted RMS error thus accounts for the nominal effect of higher order terms providing a better overall comparison among the different surface fits. Another measure of error, the adjusted coefficient of multiple determination ${ }^{9}, R_{a}{ }^{2}$, measures the proportion of variation in the response around the mean that can be attributed to terms in the model rather than to random error. It is given by

$$
R_{a}^{2}=1-\frac{\sigma_{a}^{2}}{S S_{y y} /(n-1)}
$$

where $S S_{y y}$ is the sum of squares of error about the mean of the observations. For a good fit, $R_{a}{ }^{2}$ should be closer to 1 . The RMS error, $\sigma$, for the test data is given by:

$$
\sigma=\sqrt{\frac{\sum e_{i}^{2}}{m}}
$$

In this equation $e_{i}$ is the error at the $i^{t h}$ test point and $m$ is the number of test points. For a good model the difference between $\sigma_{a}$ and $\sigma$ should not be large.

In certain cases, the number of CFD computations may not be adequate enough to spare enough data for testing the RS. Hence an alternate method to estimate the performance of the RS is to compute the PRESS statistic. The method proposed by Allen $^{20,21}$ compute a residual sum of squares. This residual is obtained by fitting a RS over the design space after dropping one design point from the training set and then comparing the RS predicted value for that point with the expected value. The PRESS rms error is given by

$\operatorname{PRESS}_{r m s}=\sqrt{\frac{\sum_{i=1}^{n}\left[y_{i}-\hat{y}_{i}\right]^{2}}{n}}$

where $y_{i}$ is the expected value, $\hat{y}_{i}$ is the value predicted by the RS for the $i^{\text {th }}$ point which is excluded while generating the $\mathrm{RS}$ and $n$ is the number of design points. If this value is close to $\sigma_{a}$ then the model performs well.

\section{Construction of Multi-Objective Optimization}

The optimization problem at hand can be formulated as 
$\min \left\{f(x), x=\left(x_{1}, x_{2}, \ldots, x_{n}\right)^{T}\right\}$

subject to $l b \leq \mathrm{x}_{\mathrm{i}} \leq u b$,

where $l b$ and $u b$ are the lower and upper bound, respectively, of the design variable $\mathrm{x}_{\mathrm{j}}$. In the current study, different combinations of the objective functions are used to investigate the issues related to multi-objective optimization. One method of optimizing multiple responses simultaneously is to build, from the individual responses, a composite response known as the desirability function'. The method allows for a designer's own priorities, on the response values, to be built into the optimization procedure. The first step in the method is to normalized the responses by develop a desirability function, $d_{i}$ for each response, $i$. In the case where a response is to be minimized the desirability takes on the form:

$d_{i}=\left(\frac{F-A}{B-A}\right)^{s}, B \leq F \leq A$

where $F$ is the prediction of the RS, $B$ is the target value and $A$ is the highest acceptable value such that $d_{i}=1$ for any $F \leq B$ and $d_{i}=O$ for $F>A$. Hence to minimize a response, this function has to be maximized. Choices for $A$ and $B$ are made according to the designer's priorities (i.e. maximum and minimum, respectively, of the individual RS, in the present study). The sensitivity of the parameter, $s$, illustrated in Figure 5 can be instructive ${ }^{9}$. Desirability functions with $s \ll 1$ imply that a product need not be close to the response target value, $B$, to be quite acceptable. But $s=8$, say, implies that the product is nearly unacceptable unless the response is close to $B$.

Value of $s$ is set based on which response has higher priority. A single composite response is developed which is the geometric mean of the desirability functions of the individual responses. The composite response is defined as:

$D=\left(d_{1} \cdot d_{2} \cdot d_{3} \ldots d_{m}\right)^{l / m}$

where $m$ is the number of objectives, which is then maximized. This approach was adopted in our previous efforts ${ }^{16}$ and has been found to be instructive.

The optimization problem is then solved using Solver, an optimization tool available as part of Microsoft Excel package $^{22}$. This tool uses the Generalized Reduced Gradient (GRG2) nonlinear optimization code developed by Lasdon et al. $^{23}$ The optimum solutions are then compared with CFD computations. Since the responses are scaled to $O(1)$, the error measures have to be accordingly scaled to estimate the accuracy of the obtained solutions. In terms of the actual values the error for a response is defined as

error $=\frac{\left|y_{C F D}-y_{R S}\right|}{y_{C F D}}$

where $y_{C F D}$ is the solution obtained from the CFD computations and $y_{R S}$ is the prediction of the RS. Using simple mathematics, not shown here, the error in the scaled variables can be written as

error $=\frac{\left|\bar{y}_{C F D}-\bar{y}_{R S}\right|}{\bar{y}_{C F D}+K}$

where the bar represents the scaled values, and $K$ is defined as

$$
K=\frac{y_{\min }}{y_{\max }-y_{\min }}
$$

where $y_{\min }$ and $y_{\max }$ are the actual minimum and maximum values, respectively, based on the available set of training and testing data for that response.

\section{RESULTS AND DISCUSSION}

\section{Grid Sensitivity Investigation}

Initially the 54 cases identified by DOE were run on an axisymmetric geometry with $336 \times 81$ nodes. Only 33 out of the 40 cases gave valid results. The rest of the results showed unsteady features, which cannot be properly captured by the steady state model employed. The RSs generated with these data for Objective-3 ( $\mathrm{TT}_{\max }$ ) and Objective-4 $\left(\mathrm{X}_{\mathrm{cc}}\right)$ had $\mathrm{R}_{\mathrm{a}}{ }^{2}$ values of 0.961 and 0.976 , respectively, suggesting a moderate fit. On checking the grid distribution in the combustion zone for cases that gave us steady state solutions, it was determined that the grid resolution was insufficient. After a series of 
tests involving addition of grid points in the axial direction in the combustion zone, a $430 \times 81$ grid was deemed appropriate and used for the second run of the optimization study. To highlight the grid refinement, a comparison of the grid distributions is shown in Figure 6. The final grid was the product of tripling the axial node density in the combustion zone. The thick lines show the initial grid density, while the thin lines show final grid density. Note that, for clarity, only every sixth j-line is shown. The RSs for Objective-3 $\left(\mathrm{TT}_{\max }\right)$ and Objective-4 $\left(\mathrm{X}_{\mathrm{cc}}\right)$ had $\mathrm{R}_{\mathrm{a}}{ }^{2}$ values of 0.989 and 0.995 , respectively, representing a considerable improvement over the RS performance based on the first, coarser grid. It is to be noted that the $\mathrm{R}_{\mathrm{a}}{ }^{2}$ values for Objective-1 $\left(\mathrm{TF}_{\mathrm{max}}\right)$ and Objective-2 $\left(\mathrm{TW}_{4}\right)$ are 0.999 for both the initial and final grid. This time, only 2 out of the 40 designs failed to provide valid results. This experience indicates that in addition to facilitating design optimization, the RSM can also help address the adequacy of the CFD solution accuracy. It offers insight into potential problems, based on the statistical regressions, based on which we can refine the computations and improve the fidelity of the individual and collective databases. Of course, this approach assumes that the given order of the RS assigned is adequate for representing the design space. While this approach by no means guarantees universally satisfactory outcomes, it suggests clear directions to assess the accuracy improvement aspect of data generation, which can be critical.

\section{Interplay of Design Variables and Impact on Design}

CFD computations are done for the 38 cases listed in Table Al and the 4 objectives are estimated. On observing the solutions, it is noted that the flow field is dominated by a large recirculation zone (Figure 7). This recirculation zone occupies the bulk of the downstream domain so as to accommodate the sudden expansion of the geometry. There is also a smaller circulation zone noticed adjacent to the injector.

A comparison between two particular Cases 12 and 44, helps demonstrate the usefulness of the proposed methodology. Table 2 shows the independent variable values and it is clear that values of the design variables vary prominently for these two cases. Normalized results for both cases, including the combustion length are also shown in Table 2 . The temperature contours for the two cases are shown in Figures 8 and 9. Results from Case 44 are shown on top and Case 12 on bottom in both figures. Figure 8 shows that the temperatures on the combustor wall and injector face for Case 44 are lower than those for Case 12 indicating desirable attributes from the life consideration. On the other hand, in the near injector region shown in Figure 9, the post tip temperature for Case 44 is higher than that for Case 12, suggesting that there is no effective improvement of life for Case 44 . Case 12 has a short combustion length, suggesting favorable performance, but has very high injector face and wall temperatures, reducing an injector's life expectancy. In Case 44, where the injector face and wall temperatures are low, a longer combustion length affects the performance. These conflicting observations in the injector details can have substantial effects on the design outcome. These observations suggest that Objective- $1\left(\mathrm{TF}_{\max }\right)$ and Objective-2 $\left(\mathrm{TW}_{4}\right)$ that reflect the life of the element follow a similar trend. This can be attributed to the larger, outer recirculation zone (Figure 7), which strips off hot combustion gases from the flame region, recirculates them back along the wall and injector face, and hence regulates Objective-1 $\left(\mathrm{TF}_{\max }\right)$ and Objective- $2\left(\mathrm{TW}_{4}\right)$. However, the third metric representing life follows a reverse trend suggesting that it is tough to obtain a design, which would be able to improve the life of the element. Also, it is apparent that neither of these designs can accommodate both performance and life at the same time. An optimization technique will be needed to guide the designer, through the competing trends exhibited by the dependent variables, to reach a logical compromise. More discussion will be made when inspecting design optimization tasks based on individual objectives.

\section{Optimization Process}

In the following, the 38 acceptable data are used to generate the RS for the 4 objective functions. Both full and reduced quadratic polynomials are generated. Table 3 identifies $\sigma_{a}$ and $\sigma$ for the different objective functions and different polynomials generated. The full quadratic model is consistent in performance in terms of both $\sigma_{a}$ and $\sigma$. The reduced quadratic models have either a poorer value of $\sigma$ or offer only marginal improvement over the full response surface model. These observations suggest that there can be modeling deficiency and/or noise in the data.

Now, considering the full quadratic models of the various objectives, the fit for Objective-1 $\left(\mathrm{TF}_{\max }\right)$, Objective- $2\left(\mathrm{TW}_{4}\right)$ and Objective-4 $\left(\mathrm{X}_{\infty \mathrm{c}}\right)$ is satisfactory, suggesting that there is no need for further improvement. However, while comparing the full quadratic RS predictions to the CFD results a spread is noticed in the plot of Objective- 3 (TT $\max$ ) (Figure 10).

Based on this observation, a cubic model is generated for Objective-3 $\left(\mathrm{TT}_{\max }\right)$. A cubic model in 4-design variable needs 35 design points. To obtain a good fit the number of design points should be considerably larger than the required number. Since there are only 38 design points available from the training set, the testing set is also included in the training set and all 52 design points are used to generate a reduced cubic model. The PRESS $_{\mathrm{rms}}$ is used to estimate the performance of the generated RMS along with the $\sigma_{a}$. Table 4 compares the performance of the quadratic and the reduced cubic models. The reduced cubic model is seen to perform better than the quadratic model. Hence this cubic model is used for Objective-3 $\left(\mathrm{TT}_{\max }\right)$ in the optimization phase. The RSs are listed in the Appendix.

Using these RSs, an optimization study is conducted to study the influence of objectives controlling life to the ones controlling performance and also to confirm the observations made before based on the CFD solutions. First each of the objectives is minimized individually (Table 5). Following this, the influence of thermal environments on the performance is 
estimated (Table 6). Next, composite optimization is performed with different weights emphasizing either the performance or life of the component (Table 7).

\section{(a) Single-Objective Optimization}

Figure 11 shows the responses and the optimum designs listed in Table 5. Since the chemical heat release is spread all over the flow field, with the aid of the large recirculation zone (Figure 7), Objective-1 $\left(\mathrm{TF}_{\max }\right)$ and Objective-2 $\left(\mathrm{TW}_{4}\right)$ correlate with each other directly (Opt-Cases 1 and 2). From this study it is clearly seen that when one of these two objectives is minimized, the other objective is low as well. However, the third metric of life, Objective- 3 (TT $\mathrm{Tax}_{\max }$ ) is high for these cases (Figure 11a). Due to conflicting trends of the temperatures, it seems difficult to obtain an optimum design based on all three life objectives. It is also noticed that when Objective-1 $\left(\mathrm{TF}_{\max }\right)$ and Objective- $2\left(\mathrm{TW}_{4}\right)$ are low, combustion length is long (Opt-Cases 1 and 2). Figure $1 \mathrm{lb}$ shows that both Objective-1 $\left(\mathrm{TF}_{\mathrm{max}}\right)$ and Objective-2 $\left(\mathrm{TW}_{4}\right)$ are minimized for low $\mathrm{H}_{2}$ flow angle and thick $\mathrm{O}_{2}$ post tip. This results in the propellants flowing in parallel just as in a shear coaxial injector, resulting in slower mixing across the shear layer and less severe thermal environment. Table 5 and Figure $1 \mathrm{lb}$ indicate that Variable-3 $(\triangle \mathrm{OA})$ exhibits different trends between Objective-1 $\left(\mathrm{TF}_{\max }\right)$ and Objective-2 $\left(\mathrm{TW}_{4}\right)$, and between Objective-3 $\left(\mathrm{TT}_{\max }\right)$ and Objective-4 $\left(\mathrm{X}_{\mathrm{cc}}\right)$, while the other three design variables behave consistently between the two groups of the objectives. As shown in Figure 12a Objective-1 $\left(\mathrm{TF}_{\max }\right)$ is less sensitive to the oxidizer flow area $(\Delta \mathrm{OA})$ than Objective-2 $\left(\mathrm{TW}_{4}\right)$. Overall, a small oxidizer flow area (Variable-3 $\left.(\triangle \mathrm{OA})=1\right)$ minimizes Objective-2 $\left(\mathrm{TW}_{4}\right)$. On the other hand, large fuel flow area, minimizes both Objective-1 $\left(\mathrm{TF}_{\max }\right)$ and Objective-2 $\left(\mathrm{TW}_{4}\right)$ (Figure $\left.11 \mathrm{~b}\right)$. Figure $12 \mathrm{~b}$ shows that Variable-3 $(\triangle \mathrm{OA})$ has opposing influence on Objective-3 $\left(\mathrm{TT}_{\max }\right)$ and Objective-4 $\left(\mathrm{X}_{\mathrm{cc}}\right)$. Objective-3 $\left(\mathrm{TT}_{\max }\right)$ is minimized for large oxidizer flow area whereas Objective- $4\left(\mathrm{X}_{\mathrm{cc}}\right)$ is minimized for small oxidizer flow area. Both Objective-3 $\left(\mathrm{TT}_{\max }\right)$ and Objective-4 $\left(\mathrm{X}_{\mathrm{cc}}\right)$ are minimized for large $\mathrm{H}_{2}$ flow angles, small fuel flow area and thin $\mathrm{O}_{2}$ post tip.

\section{(b) Multi-Objective Optimization}

To accommodate life and performance considerations, a multi-objective optimization study is carried out. Starting with Objective-4 $\left(\mathrm{X}_{\mathrm{cc}}\right)$ (performance), the objectives influencing thermal environments are added one at a time. The obtained optimum designs are presented in Table 6 and Figure 13. When Objective-3 $\left(\mathrm{TT}_{\max }\right)$ is minimized along with Objective-4 $\left(\mathrm{X}_{\mathrm{cc}}\right)$ (Opt-Case 5), the optimum design seems to favor the later (see Figure $11 \mathrm{~b}$ and Table 5). More insight can be gained by visualizing Figure $12 \mathrm{~b}$. The individual objectives drive the design towards the opposite ends of the range of Variable-3 $(\triangle \mathrm{OA})$. But the composite desirability function has marginal variation to Variable-3 $(\triangle \mathrm{OA})$. Hence, any particular value of Variable-3 $(\triangle O A)$ will not cause a large impact, and the optimum design is affected mostly by other design variables.

When Objective-1 $\left(\mathrm{TF}_{\max }\right)$ is minimized along with Objective-4 $\left(\mathrm{X}_{\mathrm{cc}}\right)$ and Objective-3 $\left(\mathrm{TT}_{\max }\right)$ (Opt-Case 6), a moderate drop in the performance is noticed. The compromise design has a high $\mathrm{H}_{2}$ flow angle, and thin $\mathrm{O}_{2}$ post tip, which favors Objective-3 $\left(\mathrm{TT}_{\max }\right.$ ) and Objective-4 $\left(\mathrm{X}_{\mathrm{cc}}\right)$ (see Figure $1 \mathrm{lb}$ and Table 5). However, the $\mathrm{H}_{2}$ flow area, Variable-2 $(\triangle \mathrm{HA})$, is large, which favors Objective-1 $\left(\mathrm{TF}_{\max }\right)$ (see Figure $11 \mathrm{~b}$ and Table 5). Addition of Objective-2 (TW 4 ) (Opt-Case 7) in the minimization process does not alter the optimum design. Figure 14a, shows clearly the reason why the Variable-2 $(\triangle \mathrm{HA})$ reaches the maximum in the present multi-objective optimization (Opt-Cases 6 and 7). Variations of Objective-1 $\left(\mathrm{TF}_{\max }\right)$ and Objective-2 $\left(\mathrm{TW}_{4}\right)$ to Variable-2 $(\Delta \mathrm{HA})$ are high as compared to the other two objectives. This drives the composite desirability function in favor of larger $\mathrm{H}_{2}$ flow area and hence lowers temperatures at the injector face and the adiabatic wall without severely degrading the performance. Figure $14 \mathrm{~b}$ shows that temperature metrics have marginal variation to the oxidizer flow area whereas the performance (Objective-4 $\left(\mathrm{X}_{\mathrm{cc}}\right)$ ) is minimized for low values of the variable. Hence the composite optimization procedure is driven in favor of (Objective-4 ( $\left.\mathrm{X}_{\mathrm{cc}}\right)$ (see Figure $1 \mathrm{lb}$ and Table 5).

To further probe the interplay between performance and life, a composite optimization study is conducted with varying weights on the objective functions. Figure 15a shows the values of the objectives for the optimum designs listed in Table 7. Opt-Cases 8 and 10 return almost the same optimum designs (Figure 15b). The optimum design also agrees with Opt-Case 7. This shows that the optimum design is reasonably robust with respect to moderate variations in weighting parameters. In Opt-Case 9 where the temperatures are weighted considerably heavier than Objective- $4\left(\mathrm{X}_{\mathrm{cc}}\right)$, the optimum design compromises between the designs obtained for Opt-Cases 1,2 and 3. The $\mathrm{H}_{2}$ flow angle is small making the propellant flow parallel to each other. At the same time, the $\mathrm{O}_{2}$ post tip is thin which lowers Objective- $3\left(\mathrm{TT}_{\max }\right)$ but increases the shear area between the propellant streams, thereby increasing the mixing rate. Hence, Objective-3 (TT $\max$ ) is not lowered to the same extent as the other temperatures. The $\mathrm{H}_{2}$ flow area favors Objective-1 $\left(\mathrm{TF}_{\max }\right)$ and Objective-2 $\left(\mathrm{TW}_{4}\right)$. Due to smaller weight assigned to Objective- $4\left(\mathrm{X}_{\mathrm{cc}}\right)$, the oxidizer flow area is not small as in Opt-Case 7 . Figure 16 shows that as the oxidizer flow area increases, performance (Objective- $4\left(\mathrm{X}_{\mathrm{cc}}\right)$ decreases. The variation of the temperatures is moderate to the oxidizer flow area. The composite desirability function which is formed with large weights on the temperatures has a marginal variation to the flow area as well. When Objective- $4\left(\mathrm{X}_{\mathrm{cc}}\right)$ is weighted considerably heavier (Opt-Case 11), the temperatures (Objective-1 $\left(\mathrm{TF}_{\max }\right)$ and Objective-2 $\left(\mathrm{TW}_{4}\right)$ ) turn out to be high. This affects the life of the injector noticeably. The optimum design has a moderate $\mathrm{H}_{2}$ flow angle and thin $\mathrm{O}_{2}$ post tip favoring performance. The results show that in cases where Objective-4 $\left(\mathrm{X}_{\mathrm{cc}}\right)$ is emphasized (Opt-Cases 8,10 and 11), the optimum $\mathrm{O}_{2}$ flow area is always low 
hence the velocity is high (Figure 15b). This results in higher mixing of the oxidizer with the fuel, when the $\mathrm{H}_{2}$ stream is aimed inward towards the $\mathrm{O}_{2}$ stream.

CFD solutions have validated the optimum designs obtained from RS for all cases. The error, as defined by Eq. 8, is marginal. The error, using Eq. 8, is to the order of about 3-4\% in the case of Objective-3 ( $\mathrm{TT}_{\max }$ ) and to the order of $1 \%$ for the other objectives. The discrepancy in Objective-3 $\left(\mathrm{TT}_{\max }\right)$ is most probably due to the steady state assumption for an unsteady problem. Opt-Case 2 shows some inconsistency in the values of Objective- $4\left(\mathrm{X}_{c c}\right)$, which is due to the unsteady features noticed in the solution.

\section{SUMMARY AND CONCLUSION}

In this study a demonstration of a CFD-based design optimization methodology for a single element rocket injector is presented. The design variables controlling the thermal environment and performance of the element are identified and the design points selected using DOE. CFD computations are carried out for each design and appropriate orders of polynomialbased response surfaces are generated for the estimated objectives. Based on the performance of the RSs a grid refinement study is carried out and a new efficient grid is generated. Following the results obtained from the CFD computations, an optimization study is carried out and correlations between different objectives are identified. Relationship between the dual goals of performance and life is studied elaborately. Shortcomings due to the steady state approximations are noticed, suggesting the requirement of developing a robust unsteady CFD model. Based on the results obtained we have reached the following conclusions.

- A large circulation in the combustion chamber distributes the heat flux over the flow field which influences the temperature on the injector face and the adiabatic wall of the combustor.

- Objective-1 $\left(\mathrm{TF}_{\max }\right)$ and Objective-2 $\left(\mathrm{TW}_{4}\right)$ are minimized for small $\mathrm{H}_{2}$ flow angle and thick $\mathrm{O}_{2}$ post tip. The thick $\mathrm{O}_{2}$ post tip increases the area for heat transfer and hence, Objective-3 $\left(\mathrm{TT}_{\max }\right)$ is high. Additionally, Objective- $3\left(\mathrm{TT}_{\max }\right)$ is minimized for a design which maximizes Objective-1 $\left(\mathrm{TF}_{\max }\right)$ and Objective-2 $\left(\mathrm{TW}_{4}\right)$. This conflicting trend makes the optimization based on life a challenge. When all the life metrics are given importance, a design similar to a shear coaxial injector is obtained with thin $\mathrm{O}_{2}$ post tip.

- Optimization of the injector design based on Objective-1 $\left(\mathrm{TF}_{\max }\right)$ or Objective-2 $\left(\mathrm{TW}_{4}\right)$, results in a design similar to a shear coaxial injector, whereas the one based on Objective-4 $\left(\mathrm{X}_{\mathrm{cc}}\right)$ (performance metric) results in a design similar to an impinging injector.

- Optimization study provides insight into the interplay of the design variables and objectives. For example, when individually optimized, Objective-3 $\left(\mathrm{TT}_{\max }\right)$ and Objective-4 $\left(\mathrm{X}_{\mathrm{cc}}\right)$ responds to Variable-3 $(\Delta \mathrm{OA})$ differently. But the sensitivity of the desirability function, combining the two objectives, to Variable-3 $(\triangle \mathrm{OA})$ is marginal, allowing the design to assume flexible value of Variable-3 $(\triangle \mathrm{OA})$ without causing large impact. Sensitivity of Objective-1 $\left(\mathrm{TF}_{\max }\right)$ and Objective-2 $\left(\mathrm{TW}_{4}\right)$ to Variable-2 $(\triangle \mathrm{HA})$ is high as compared to the other two objectives, which drives the composite desirability function based on all four objectives in favor of larger $\mathrm{H}_{2}$ flow area without severely degrading the performance. When the optimization process is biased towards either the performance or the life metrics, it deteriorates the other. For example, when the life metrics are weighed heavily a compromise design is obtained which is similar to a shear coaxial injector with a thin $\mathrm{O}_{2}$ post tip that has a long combustion length.

- It seems that the best compromise is obtained by weighing the life and performance metrics equally. It results in a design which is similar to an impinging injector with thin $\mathrm{O}_{2}$ post tip.

- Finally, RS can aid in judging the quality of the CFD solution and help improve modeling issues, for e.g. improving grid quality.

\section{ACKNOWLEGEMENTS}

This study has been supported in part by NASA Marshall Space Flight Center. The authors would also like to acknowledge Dr. Raphael T. Haftka for his valuable suggestions.

\section{REFERENCES}

1. Rupe, J. H., “An Experimental Correlation of the Nonreactive Properties of Injection Schemes and Combustion Effects in a Liquid Rocket Engine," NASA TR 32-255, 1965.

2. Pieper, J. L., "Oxygen/Hydrocarbon Injector Characterization," PL-TR 91-3029, October, 1991.

3. Nurick, J. H., "DROPMIX - A PC Based Program for Rocket Engine Injector Design," JANNAF Propulsion Conference, Cheyenne, Wyoming, 1990.

4. Dickerson, R., Tate, K., Nurick, W., "Correlation of Spray Injector Parameters with Rocket Engine Performance," AFRPL-TR-68-11, January 1968. 
5. Pavli, A. L., "Design and Evaluation of High Performance Rocket Engine Injectors for Use with Hydrocarbon Fuels," NASA TM 79319, 1979.

6. Calhoon, D., F. Ito, J. I. and Kors, D. L., "Investigation of Gaseous propellant Combustion and Associated InjectorChamber Design Guidelines," Aerojet liquid rocket company, NASA Cr-121234, Contract NAS3-13379, July 1973.

7. Cheng, G.C., and Farmer, R.C., "CFD Spray Combustion Model for Liquid Rocket Engine Injector Analyses," AIAA Paper 2002-0785, 40th AIAA Aerospace Sciences Meeting \& Exhibit, Jan. 14-17, 2002.

8. Gill, D. S. and Nurick, W. H., "Liquid Rocket Engine Injectors," NASA SP-8089, NASA Lewis Research Center, March, 1976.

9. Myers, R. H., and Montgomery, D. C., Response Surface Methodology - Process and Product Optimization Using Designed Experiment, John Wiley \& Sons, 1995.

10. JMP ${ }^{\circledast}$ Design of Experiments, Version 5, Copyright $\odot$ 2002, SAS Institute Inc., Cary, NC, USA.

11. Calhoon, D. F., Ito, J. I. and Kors, D. L., "Handbook for Design of Gaseous Propellant Injectors and Combustion Chambers," 1973.

12. Chen, Y. S., "Compressible and Incompressible Flow Computation with a Pressure-Based Method," AIAA89-0286, AIAA 28th Aerospace Sciences Meeting, January 9-12, 1989.

13. Wang, T. S. and Chen, Y. S., "A United Navier-Stokes Flowfield and performance Analysis of Liquid Rocket Engines," AIAA 90-2494, AIAA 26th Joint Propulsion Conference, July 16-18, 1990.

14. Chen, Y. S. and Farmer, R. C., "CFD Analysis of Baffle Flame Stabilization," AIAA 91-1967, AIAA 27th Joint Propulsion Conference, June 24-26, 1991.

15. Owen, A., "Orthogonal Arrays for: Computer Experiments, Integration and Visualization," Statistica Sinica, Vol. 2, No.2, pp. 439-452, 1992.

16. Shyy. W., Papila, N., Vaidyanathan, R. and Tucker, K., Global Design Optimization for Aerodynamics and Rocket Propulsion Components, Progress in Aerospace Sciences Vol. 37 (2001), pages 59-118

17. Papila, N. U., Neural Network and Polynomial-Based Response Surface Techniques or Supersonic Turbine Design Optimization, PhD Dissertation, University of Florida, 2001.

18. Mullin, M. and Sukthankar, R., "Complete Cross-Validation for Nearest Neighbor Classifiers," 17th International Conference on Machine Learning (ICML), Stanford, California, 2000.

19. JMP ${ }^{\mathrm{TM}}$, The Statistical Discovery Software ${ }^{\mathrm{TM}}$, Version 5, Copyright $($ C) 1989-2002, SAS Institute Inc., Cary, NC, USA.

20. Allen, D. M., "Mean Square Error of Prediction as a Criterion for Selecting Variables," Technometrics, 13, pages 469475, 1971.

21. Allen, D. M., "The Relationship Between Variable Selection and Data Augmentation and a Method for Prediction," Technometrics, 16, pages 125-127, 1974.

22. Microsoft® Excel 2000, Copyright (C) 1985-1999, Microsoft Corporation, Seattle, WA.

23. Lasdon, L.S, Waren, A., Jain, A., and Ratner, M., "Design and Testing of a Generalized Reduced Gradient Code for Nonlinear Programming," ACM Transactions on Mathematical Software 4:1, 1978.

\begin{tabular}{|c|c|c|c|c|}
\hline \multirow[t]{2}{*}{ Variable } & \multicolumn{2}{|c|}{ Minimum } & \multicolumn{2}{|c|}{ Maximum } \\
\hline & Actual & Normalized & Actual & Normalized \\
\hline$\alpha$ & $0^{\circ}$ & 0 & $20^{\circ}$ & 1 \\
\hline$\overline{\Delta H A}$ & Baseline & 0 & Baseline $+25 \%$ & 1 \\
\hline $\mathbf{\Delta O A}$ & Baseline- $40 \%$ & 0 & Baseline & 1 \\
\hline OPTT & $0.01 \mathrm{in}$ & $\overline{0}$ & 0.02 in & 1 \\
\hline
\end{tabular}

\begin{tabular}{|c|c|c|c|c|c|c|c|c|}
\hline Case & $\boldsymbol{\alpha}$ & $\Delta \mathbf{H A}$ & $\Delta \mathbf{O A}$ & $\mathbf{O P T T}$ & $\mathbf{T F}_{\max }$ & $\mathbf{T W}_{\mathbf{4}}$ & $\mathbf{T T}_{\max }$ & $\mathbf{X}_{\mathbf{c c}}$ \\
\hline 12 & 1 & 0 & 0 & 0 & 0.998 & 0.927 & 0.128 & -0.004 \\
\hline 44 & 0 & 0.5 & 0.5 & 1 & 0.285 & 0.395 & 0.923 & 0.567 \\
\hline
\end{tabular}

Table 2. Independent and dependent variable (Objectives) for Cases 12 and 44 from CFD computations \{Normalized values shown\}. 


\begin{tabular}{|c|c|c|c|}
\hline & & Full quadratic RS & Reduced quadratic model \\
\hline \multirow[t]{4}{*}{$T F_{\max }$} & Number of observations & 38 & 38 \\
\hline & $\sigma_{\mathrm{a}}$ & 0.00566 & 0.00546 \\
\hline & $\sigma(14$ points $)$ & 0.00460 & 0.00463 \\
\hline & Mean & \multicolumn{2}{|c|}{0.495} \\
\hline \multirow[t]{4}{*}{$T W_{4}$} & Number of observations & 38 & 38 \\
\hline & $\sigma_{a}$ & 0.00803 & 0.00795 \\
\hline & $\sigma$ (14 points) & 0.00669 & 0.00799 \\
\hline & Mean & \multicolumn{2}{|c|}{0.514} \\
\hline \multirow[t]{4}{*}{$T T_{\max }$} & Number of observations & 38 & 38 \\
\hline & $\sigma_{\mathrm{a}}$ & 0.0413 & 0.0401 \\
\hline & $\sigma(14$ points $)$ & 0.0396 & 0.0382 \\
\hline & Mean & \multicolumn{2}{|c|}{0.560} \\
\hline \multirow[t]{4}{*}{$X_{c c}$} & Number of observations & 38 & 38 \\
\hline & $\sigma_{\mathrm{a}}$ & 0.0205 & 0.0197 \\
\hline & $\sigma(14$ points $)$ & 0.0178 & 0.0186 \\
\hline & Mean & \multicolumn{2}{|c|}{0.497} \\
\hline
\end{tabular}

Table 3: Performance of full and reduced quadratic RSs for the four objective functions (Non-normalized values used\}.

\begin{tabular}{|c|c|c|c|}
\hline & & Full quadratic RS & Reduced cubic RS \\
\hline \multirow{3}{*}{$\boldsymbol{T} T_{\max }$} & Number of observations & 38 & 52 \\
\cline { 2 - 4 } & $\sigma_{\mathrm{a}}$ & 0.0413 & 0.0303 \\
\cline { 2 - 4 } & PRESS & 0.0521 & 0.0388 \\
\cline { 2 - 4 } & Mean & 0.560 & 0.591 \\
\hline
\end{tabular}

Table 4: Performance of RSs for the $\mathrm{TT}_{\max }$. Reduced cubic RS has 21 coefficients [Non-normalized values used].

\begin{tabular}{|c|c|c|c|c|c|c|c|c|}
\hline Opt-Case & $\boldsymbol{\alpha}$ & $\mathbf{\Delta H A}$ & $\mathbf{\Delta O A}$ & $\mathbf{O P T T}$ & $\mathbf{T F}_{\max }$ & $\mathbf{T W}_{\mathbf{4}}$ & $\mathbf{T T}_{\max }$ & $\mathbf{X}_{\mathrm{cc}}$ \\
\hline 1 & 0 & 1 & 0.592 & 1 & $0.0(1)$ & $0.0725(0)$ & $0.914(0)$ & $0.769(0)$ \\
\hline CFD & & & & & -0.00207 & 0.0656 & 0.936 & 0.758 \\
\hline error (\%) & & & & & 0.11 & 0.08 & 0.70 & 0.25 \\
\hline 2 & 0 & 1 & 0 & 1 & $0.0309(0)$ & $0.0(1)$ & $1.0(0)$ & $0.440(0)$ \\
\hline CFD & & & & & 0.091 & 0.0461 & 0.911 & 0.568 \\
\hline error (\%) & & & & & 0.90 & 0.57 & 2.84 & 2.93 \\
\hline 3 & 1 & 0 & 1 & 0 & $0.944(0)$ & $0.976(0)$ & $0.0(1)$ & $0.153(0)$ \\
\hline CFD & & & & & 0.943 & 0.969 & 0.103 & 0.158 \\
\hline error (\%) & & & & & 0.01 & 0.08 & 4.46 & 0.12 \\
\hline 4 & 0.917 & 0 & 0 & 0 & $0.987(0)$ & $0.926(0)$ & $0.182(0)$ & $0.0(1)$ \\
\hline CFD & & & & & 0.981 & 0.919 & 0.119 & -0.004 \\
\hline error (\%) & & & & & 0.08 & 0.08 & 2.69 & 0.12 \\
\hline
\end{tabular}

Table 5: Minimizing individual objectives. Value in parenthesis (1) indicates which objective function is minimized (Normalized values shown\}. 


\begin{tabular}{|c|c|c|c|c|c|c|c|c|}
\hline Opt-Case & $\alpha$ & $\mathbf{\Delta H A}$ & $\Delta \mathbf{O A}$ & $\mathbf{O P T T}$ & $\mathbf{T F}_{\max }$ & $\mathbf{T W}_{\mathbf{4}}$ & $\mathbf{T T}_{\max }$ & $\mathbf{X}_{\mathrm{cc}}$ \\
\hline 4 & 0.917 & 0 & 0 & 0 & $0.987(0)$ & $0.926(0)$ & $0.182(0)$ & $0.0(1)$ \\
\hline CFD & & & & & 0.981 & 0.919 & 0.119 & -0.004 \\
\hline error (\%) & & & & & 0.08 & 0.08 & 2.69 & 0.12 \\
\hline 5 & 1 & 0 & 0 & 0 & $1.0(0)$ & $0.928(0)$ & $0.151(1)$ & $0.00097(1)$ \\
\hline CFD & & & & & 0.998 & 0.927 & 0.128 & -0.004 \\
\hline error (\%) & & & & & 0.03 & 0.01 & 1.00 & 0.14 \\
\hline 6 & 1 & 1 & 0 & 0 & $0.376(1)$ & $0.224(0)$ & $0.155(1)$ & $0.279(1)$ \\
\hline CFD & & & & & 0.369 & 0.214 & 0.252 & 0.264 \\
\hline error (\%) & & & & & 0.10 & 0.12 & 3.93 & 0.38 \\
\hline 7 & 1 & 1 & 0 & 0 & $0.376(1)$ & $0.224(1)$ & $0.155(1)$ & $0.279(1)$ \\
\hline CFD & & & & & 0.369 & 0.214 & 0.252 & 0.264 \\
\hline error (\%) & & & & & 0.10 & 0.12 & 3.93 & 0.38 \\
\hline
\end{tabular}

Table 6: Study of effect of life on performance. Value in parenthesis indicates the weighting on the objective functions \{Normalized values shown\}.

\begin{tabular}{|c|c|c|c|c|c|c|c|c|}
\hline Opt-Case & $\alpha$ & $\Delta \mathbf{H A}$ & $\mathbf{\Delta O A}$ & $\mathbf{O P T T}$ & $\mathbf{T F}_{\max }$ & $\mathbf{T W}_{\mathbf{4}}$ & $\mathbf{T T}_{\max }$ & $\mathbf{X}_{\mathbf{c c}}$ \\
\hline 8 & 1 & 1 & 0.192 & 0 & $0.346(1)$ & $0.210(1)$ & $0.163(1)$ & $0.334(0.5)$ \\
\hline CFD & & & & & & & & \\
\hline error (\%) & & & & & & & & \\
\hline 9 & 0 & 1 & 0.497 & 0 & $0.0451(5)$ & $0.0823(5)$ & $0.471(5)$ & $0.627(0.1)$ \\
\hline CFD & & & & & & & & \\
\hline error (\%) & & & & & & & & \\
\hline 10 & 1 & 1 & 0 & 0 & $0.376(0.5)$ & $0.224(0.5)$ & $0.155(0.5)$ & $0.279(1)$ \\
\hline CFD & & & & & 0.369 & 0.214 & 0.252 & 0.264 \\
\hline error (\%) & & & & & 0.10 & 0.12 & 3.93 & 0.38 \\
\hline 11 & 0.612 & 0 & 0 & 0 & $0.919(0.1)$ & $0.898(0.1)$ & $0.281(0.1)$ & $0.0132(5)$ \\
\hline CFD & & & & & & & & \\
\hline error (\%) & & & & & & & & \\
\hline
\end{tabular}

Table 7: Study of influence of life and performance objectives on each other. Value in parenthesis indicates the weighting on the objective functions \{Normalized values shown\}. 


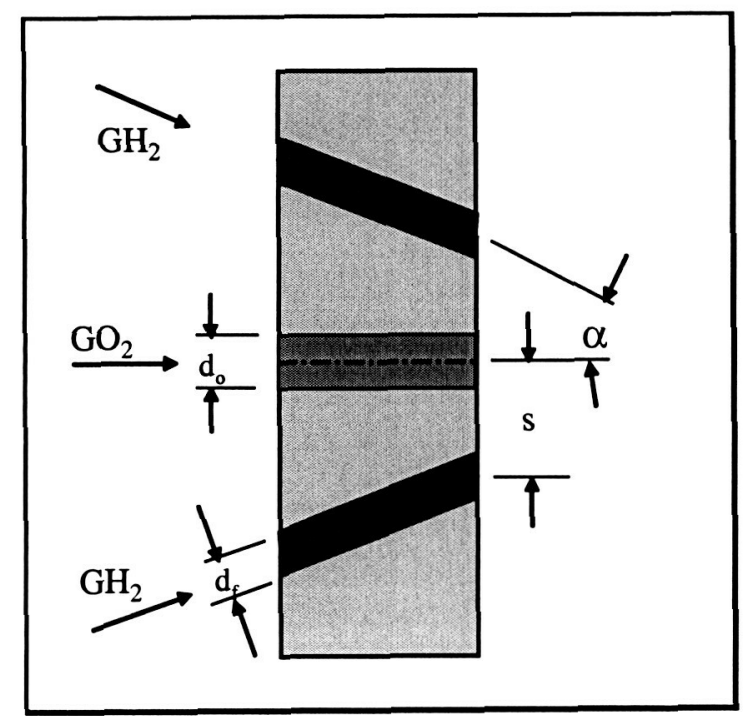

(a)

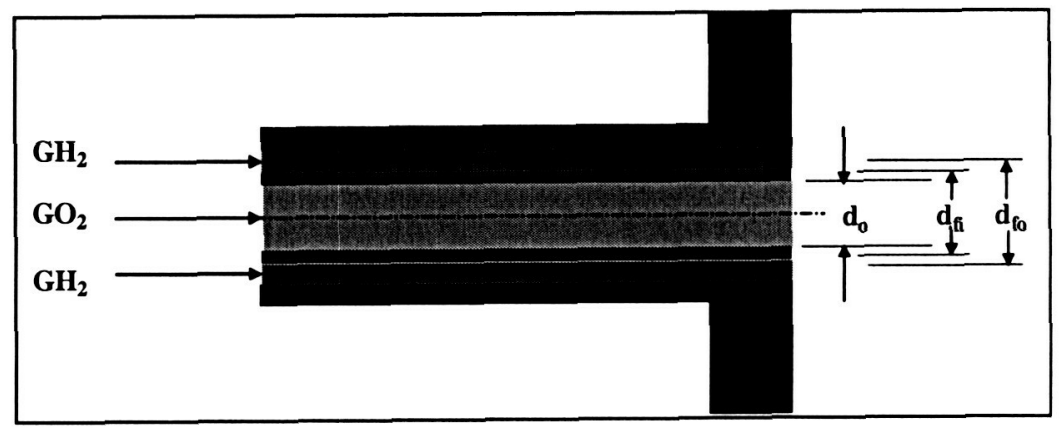

(b)

Figure 1: (a) $\mathrm{GO}_{2} / \mathrm{GH}_{2}$ F-O-F Impinging Element, (b) $\mathrm{GO}_{2} / \mathrm{GH}_{2}$ Coaxial Element.

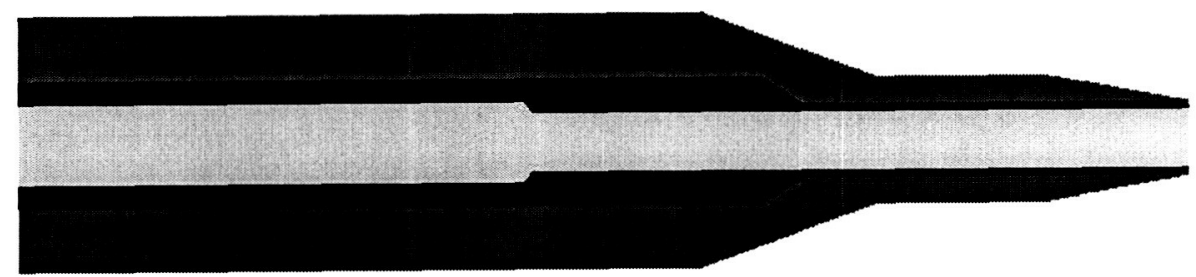

Figure 2: Schematic of Hybrid Boeing Element (U. S. Patent 6253539)

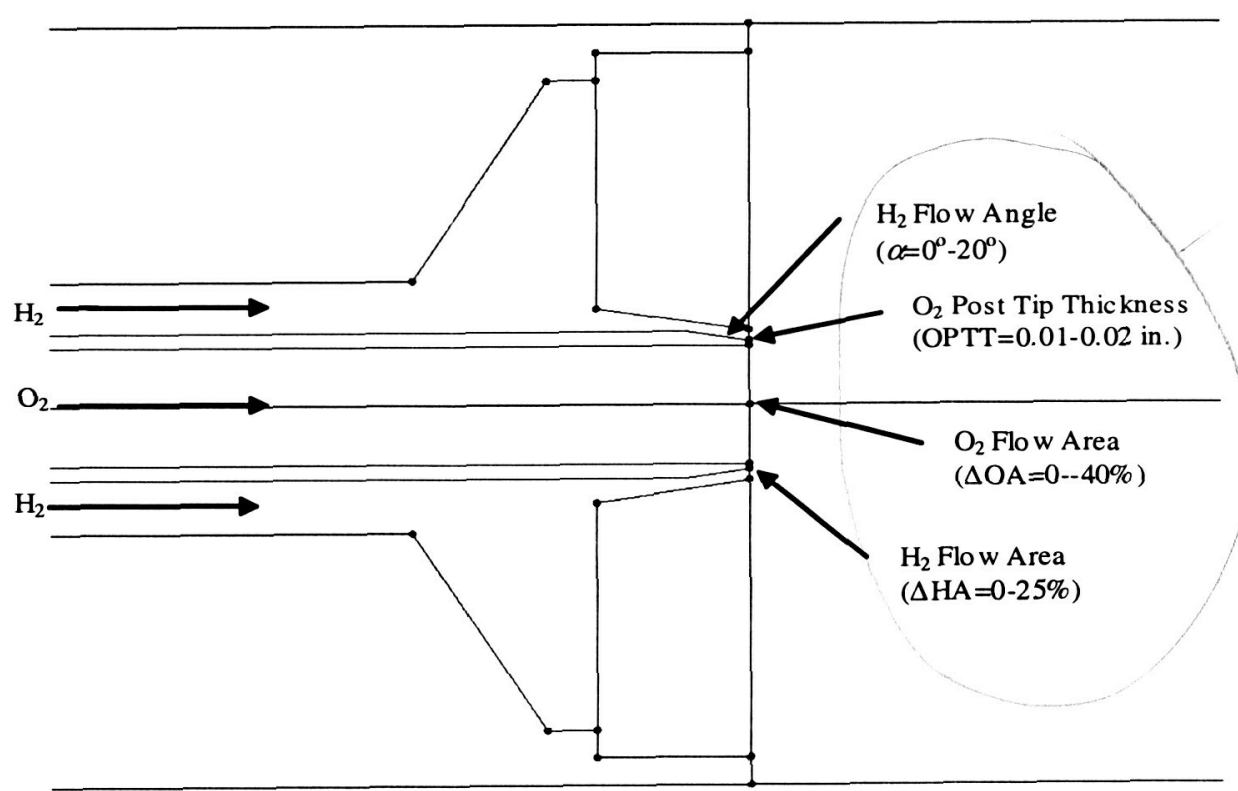

Figure 3: (a) Objective functions 


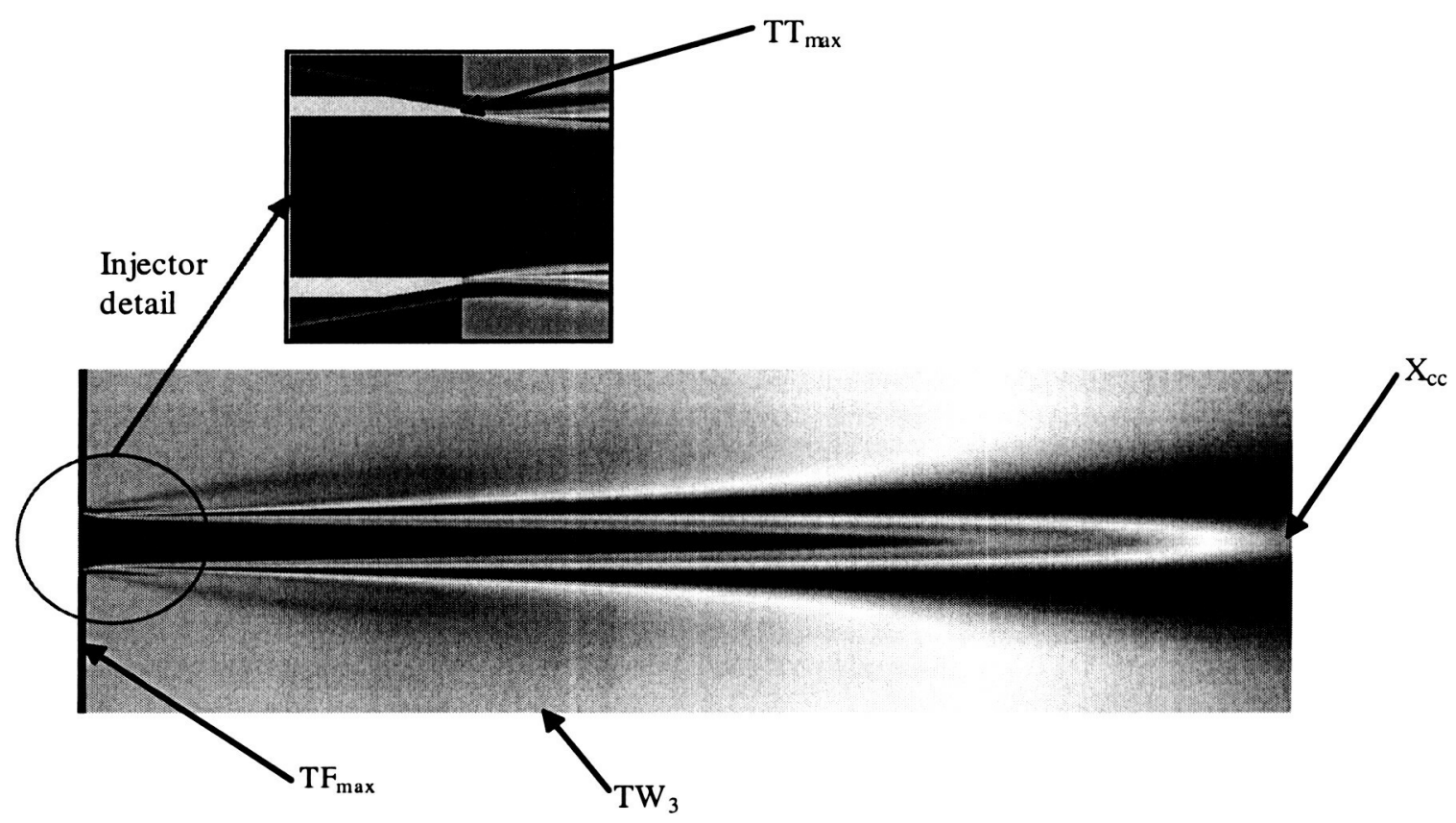

Figure 3: (b) Design Variables and their range.

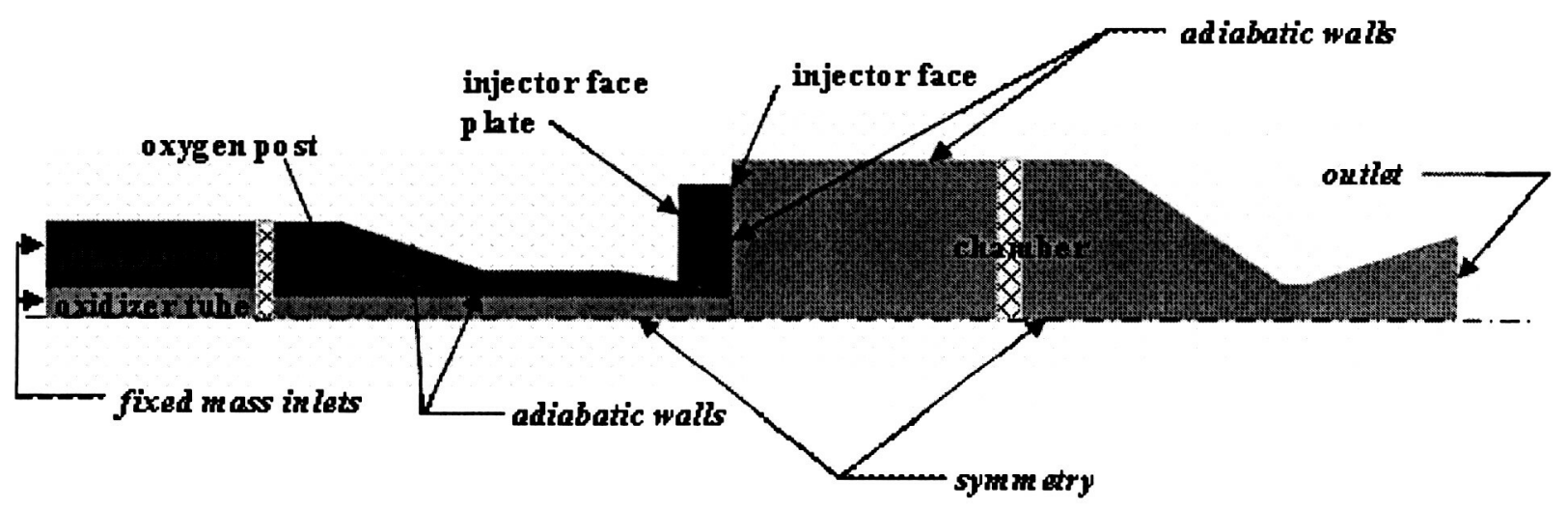

Figure 4: Simulation domain and boundary conditions 


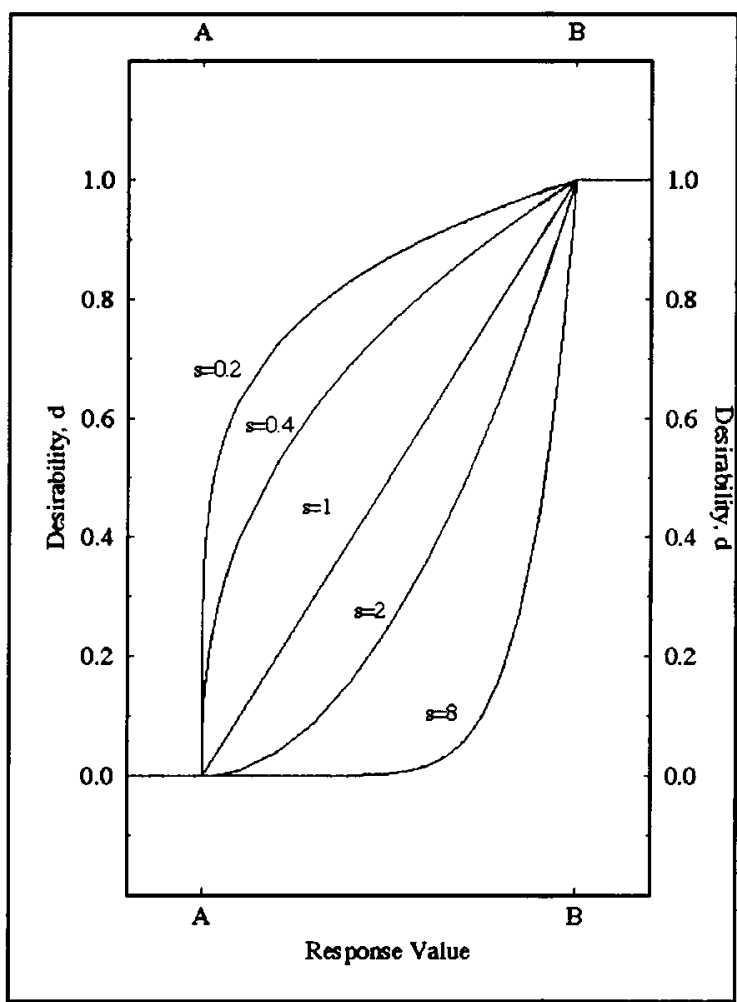

Figure 5: Desirability function (d) for various weight factors, s. (Note: $\mathrm{B}<\mathrm{A}$ ) ${ }^{9}$

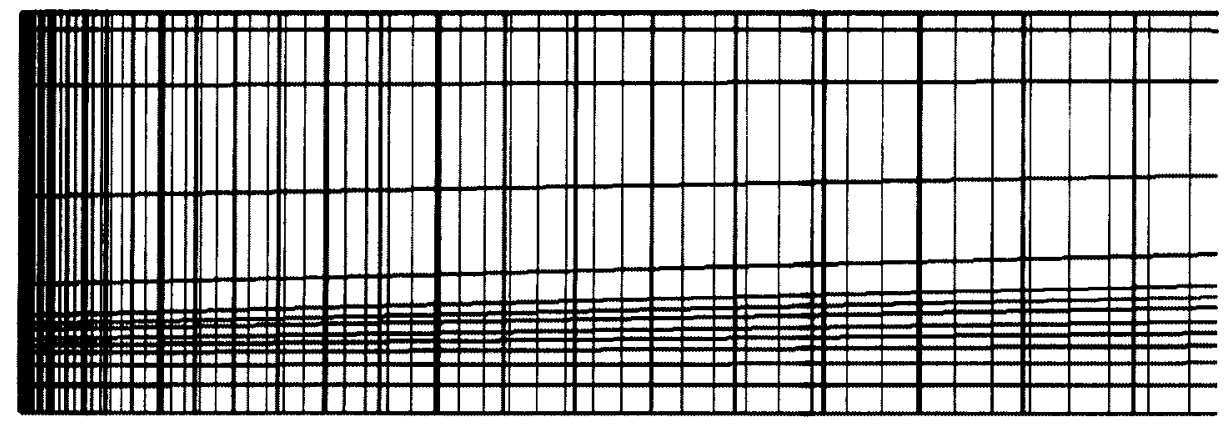

Figure 6: Comparing the unrefined $(336 \times 81)$ \{thicker lines\} and refined $(430 \times 81)$ \{thinner lines\} grids. 


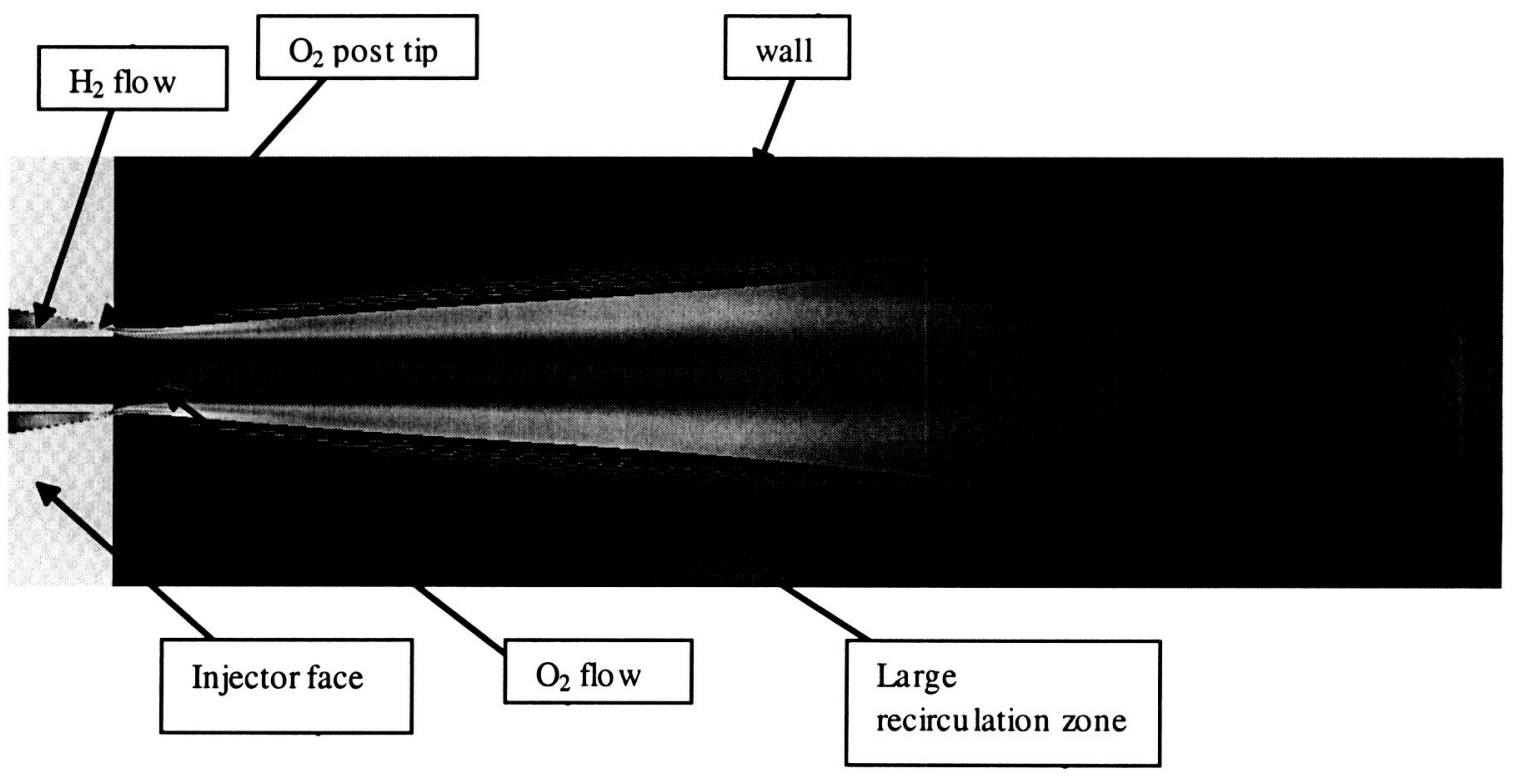

Figure 7: Large recirculation zone in the combustion chamber.

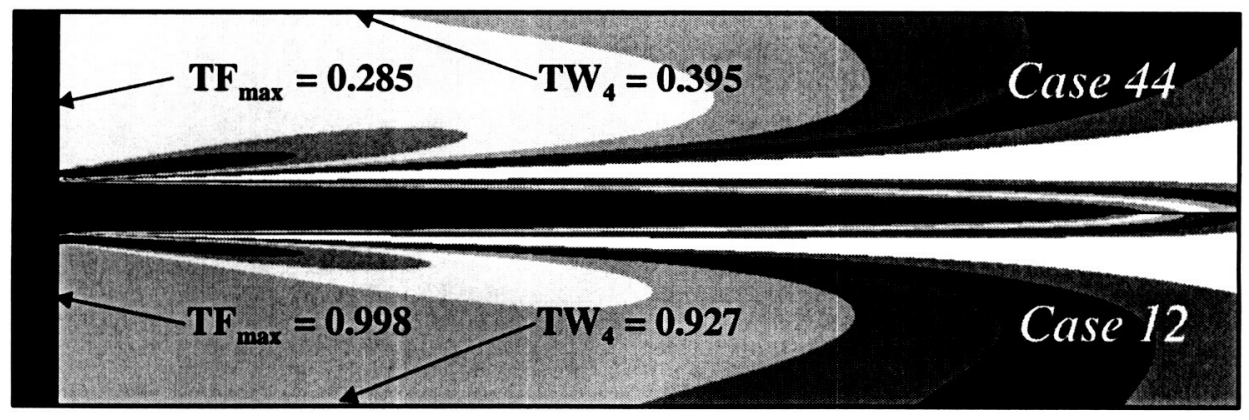

Figure 8: Temperature Field for Cases 12 and 44. 


\section{Case 44}

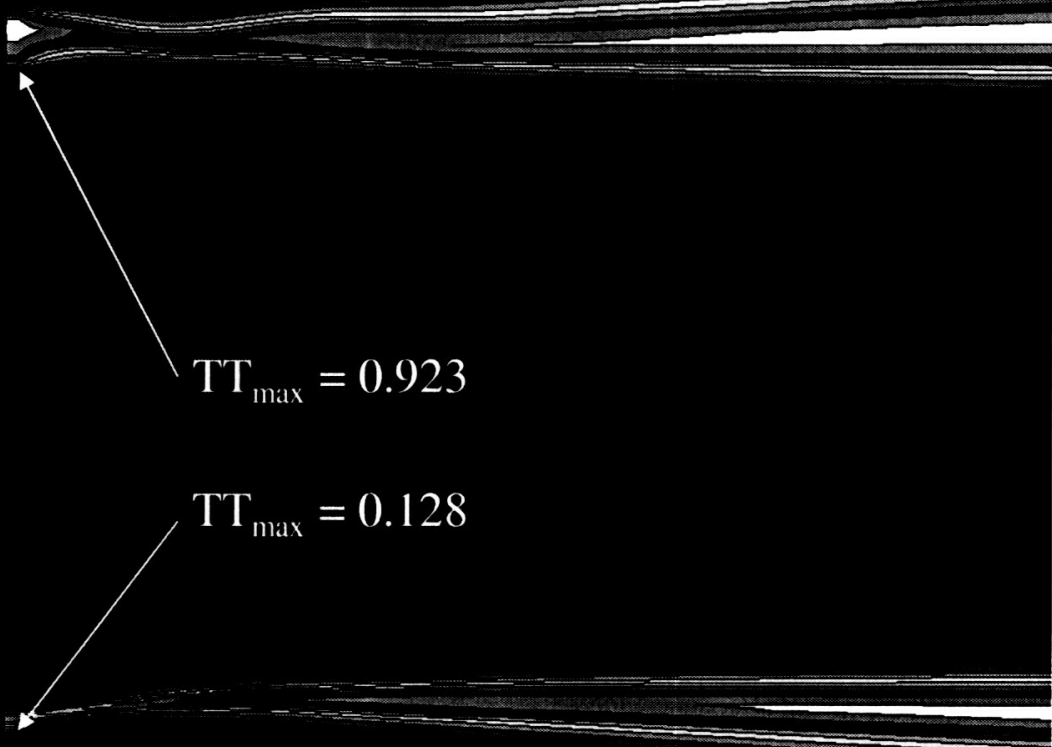

\section{Case 12}

Figure 9: Near-Injector Temperature Field for Cases 12 and 44.

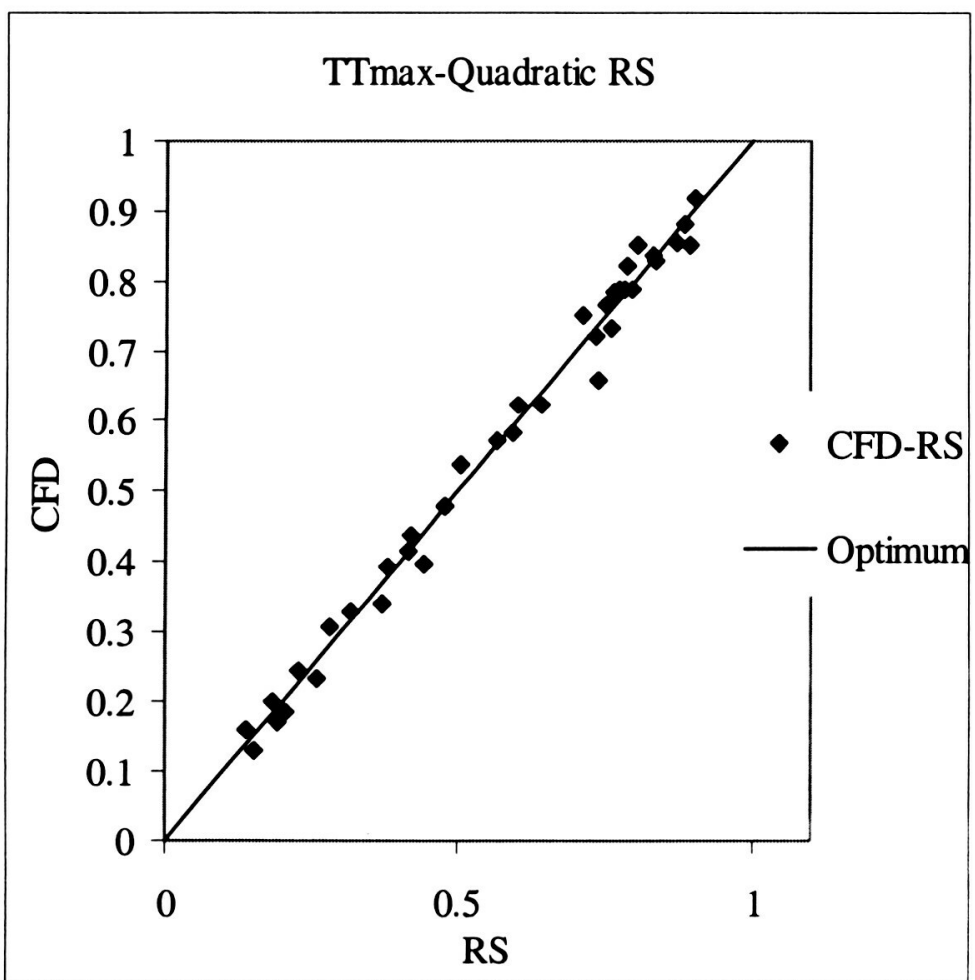

Figure 10: Comparison between the best fit possible and as predicted by quadratic response surface for $\mathrm{TT}_{\max }$. Optimum refers to the case when RS and CFD values are identical. CFD-RS represents the value as for the current case (Normalized values shown). 


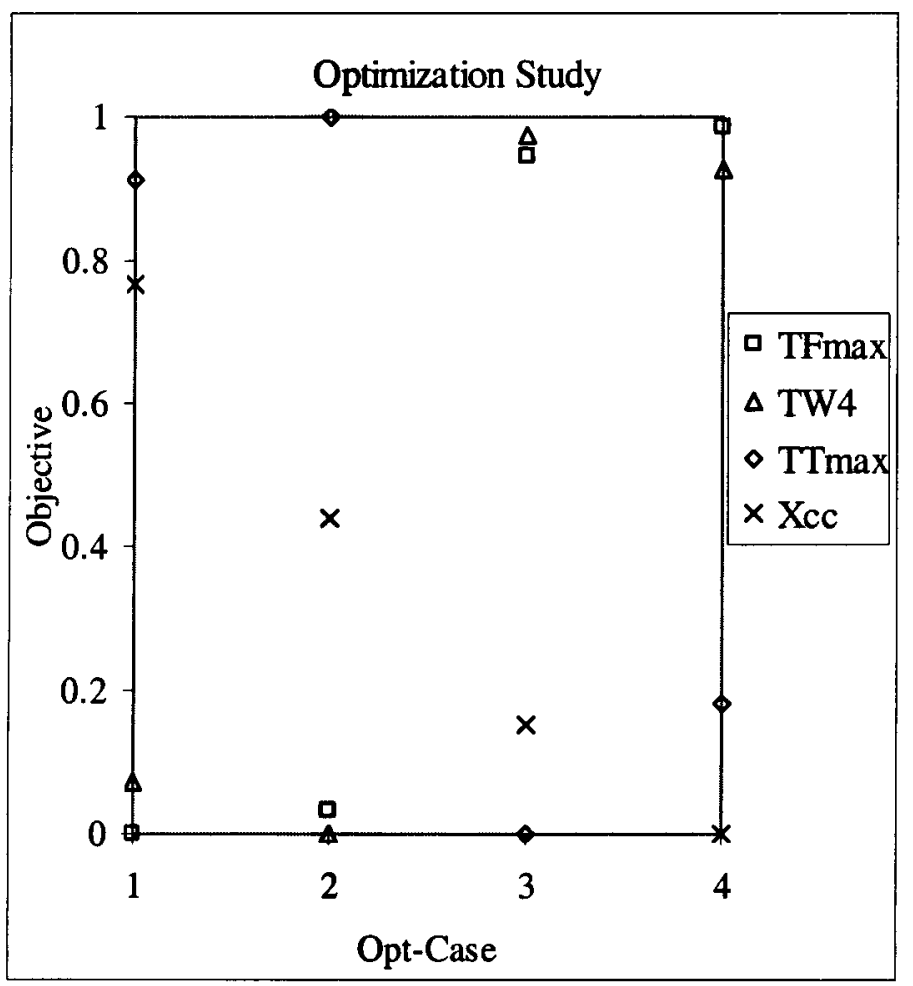

(a)

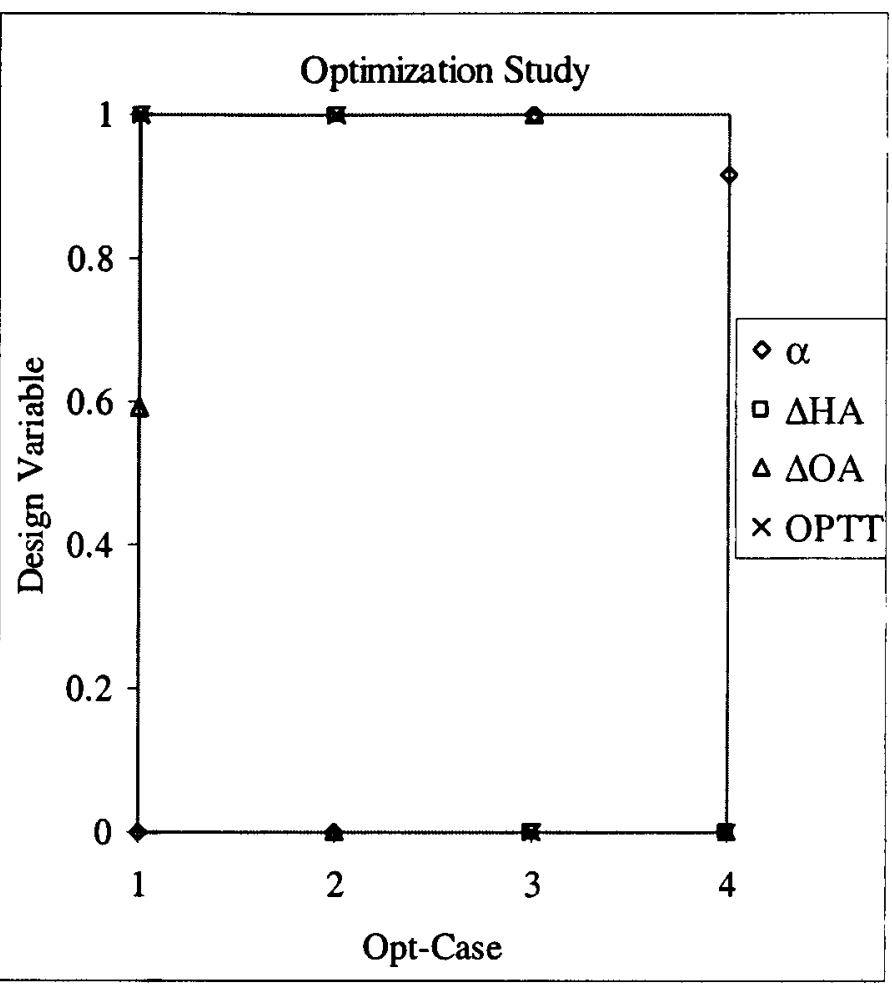

(b)

Figure 11: Minimization of different objectives. (Case 1: $\mathrm{TF}_{\max }$, Case 2: $\mathrm{TW}_{4}$, Case 3: $\mathrm{TT}_{\max }$, Case 4: $\mathrm{X}_{\mathrm{cc}}$ ) (a) Objectives, (b) Design Variables \{Normalized values shown\}.

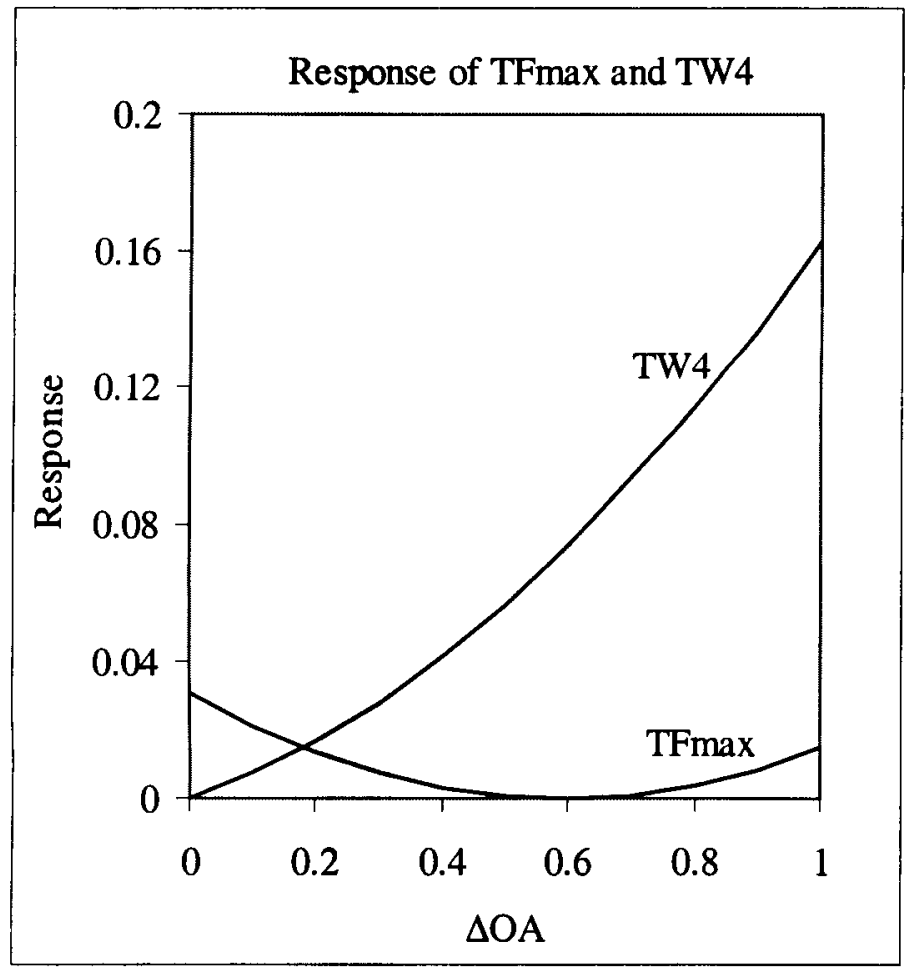

(a)

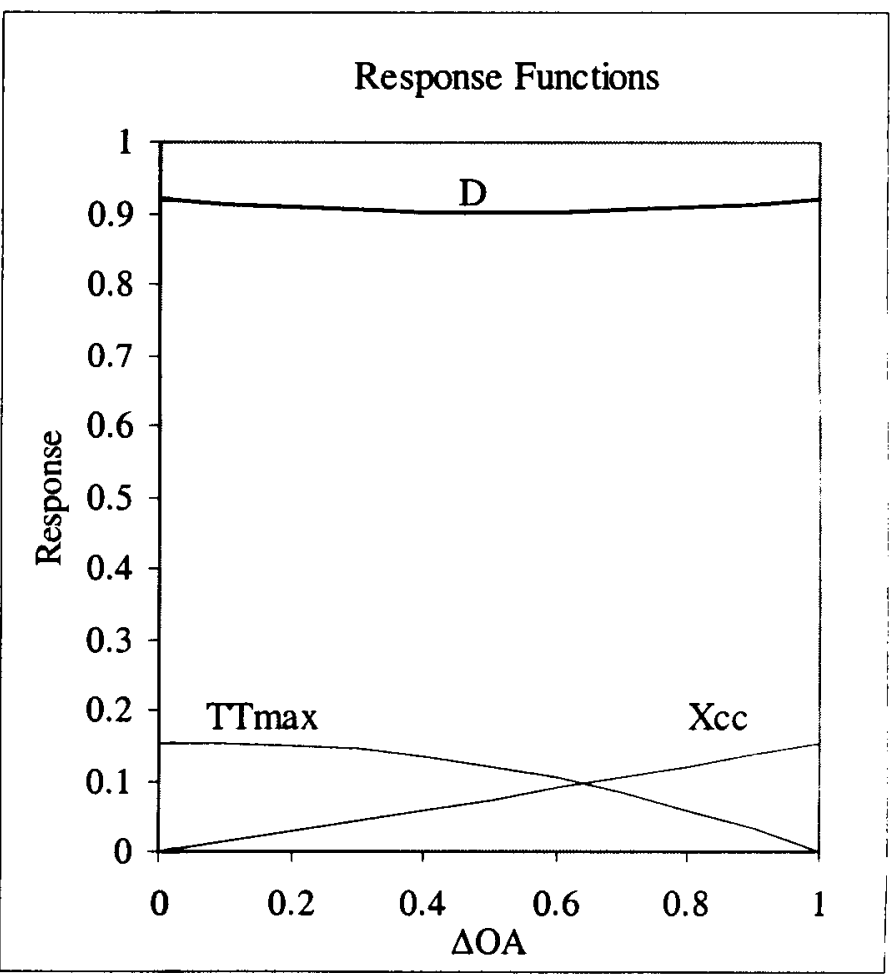

(b)

Figure 12: Variation of (a) $\mathrm{TF}_{\max }$ and $\mathrm{TW}_{4}$ for $\alpha=0, \Delta \mathrm{HA}=1$ and OPTT=1, (b) $\mathrm{TT}_{\max }$ and $\mathrm{X}_{\mathrm{cc}}$ for $\alpha=1, \Delta \mathrm{HA}=0$ and $O P T T=0$, with respect to $\triangle O A$ \{Normalized values shown and $D$ is the desirability function\}. 


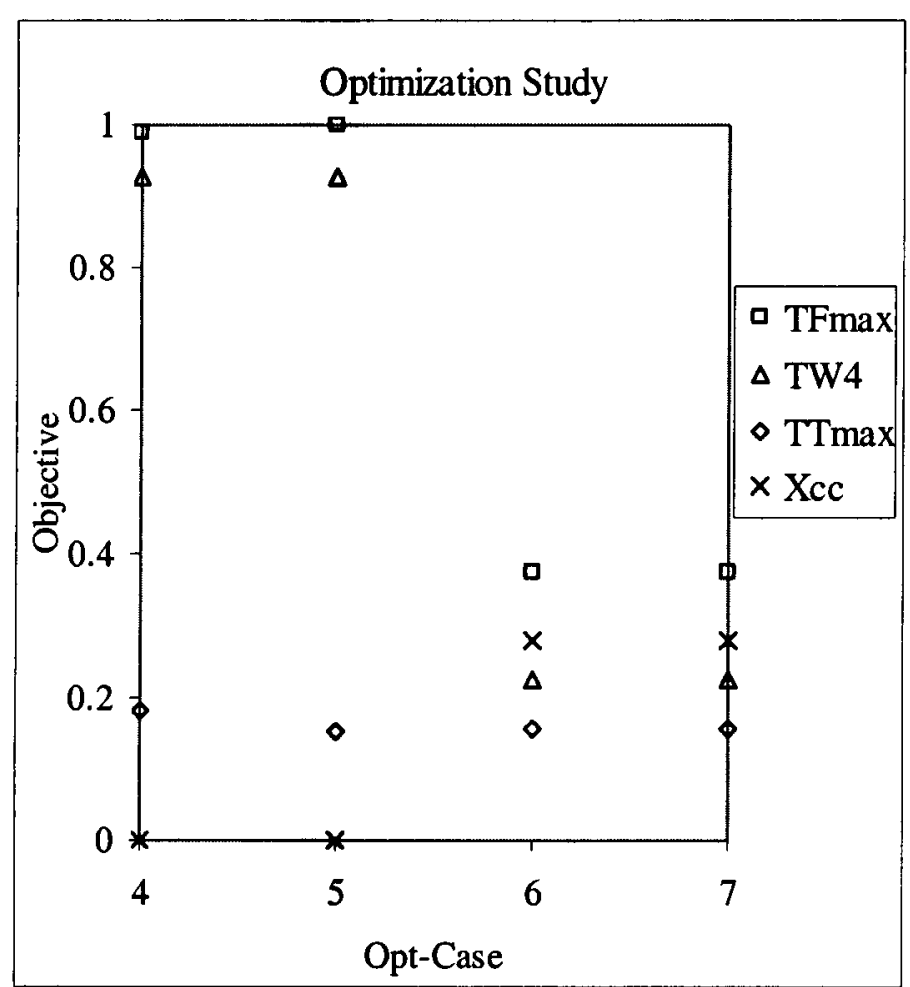

(a)

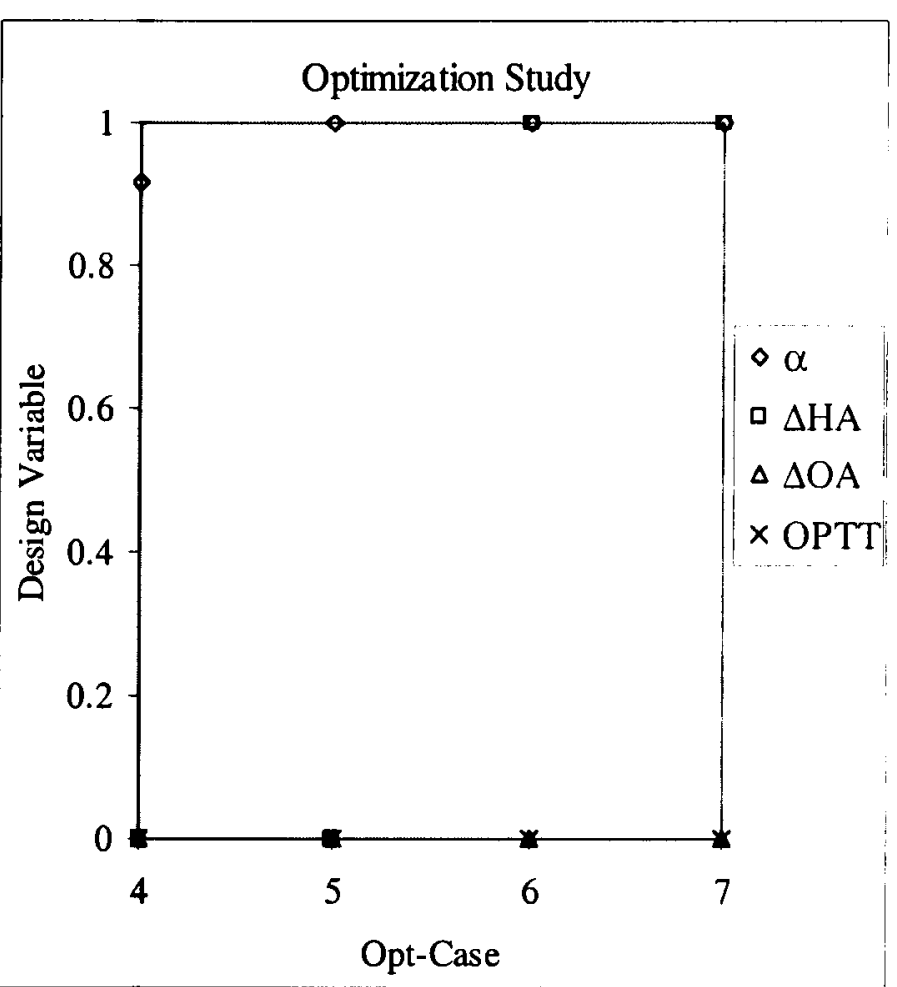

(b)

Figure 13: Composite minimization of objectives with different weightings.(Case $4:(0,0,0,1)$, Case $5:(0,0,1,1)$, Case 6 :

$(1,0,1,1)$, Case $7:(1,1,1,1)$,) \{The values in parenthesis indicates weights for $\left(\mathrm{TF}_{\max }, \mathrm{TW}_{4}, \mathrm{TT}_{\max }, \mathrm{X}_{\mathrm{cc}}\right)$ \},

(a) Objectives, (b) Design Variables \{Normalized values shown\}.

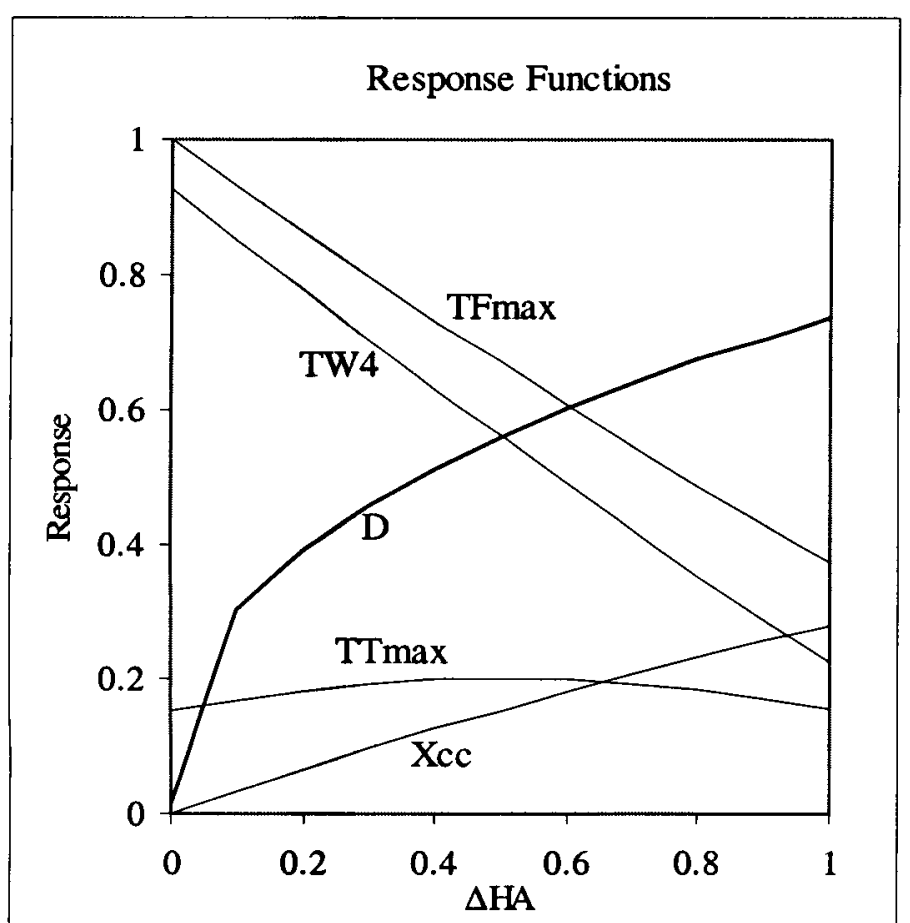

(a)

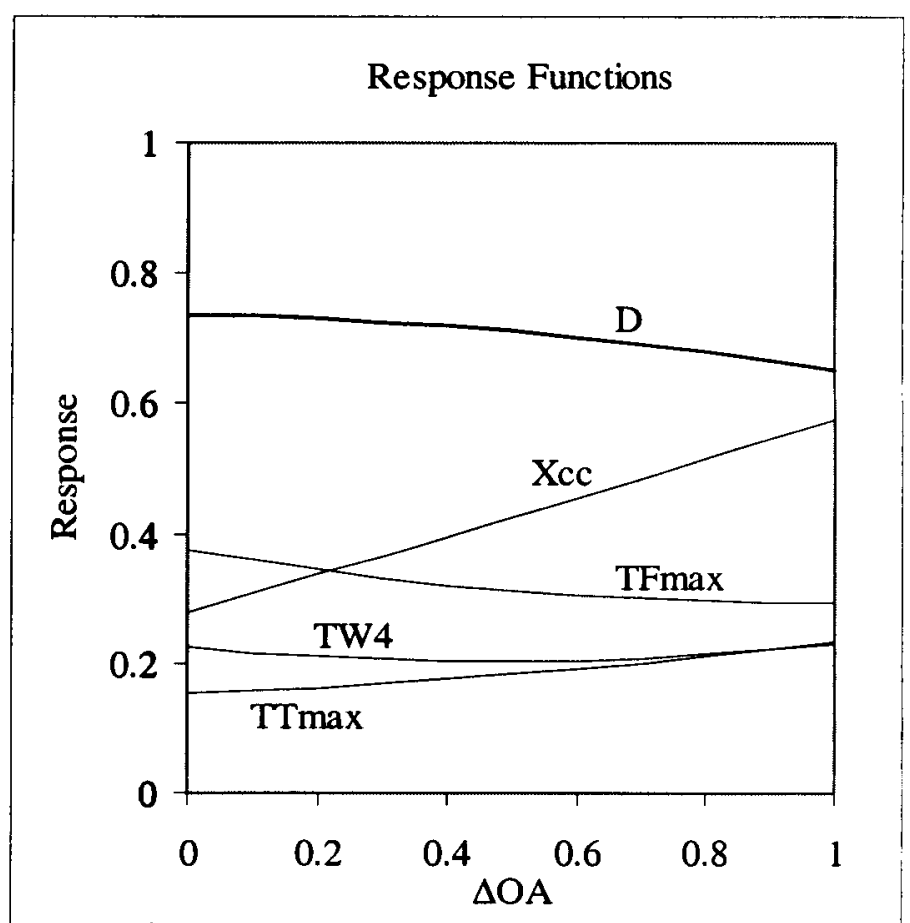

(b)

Figure 14: Variation of (a) $\mathrm{TF}_{\max }, \mathrm{TW}_{4}, \mathrm{TT}_{\max }$ and $\mathrm{X}_{\mathrm{cc}}$, with respect to $\Delta \mathrm{HA}$ for $\alpha=1, \Delta \mathrm{OA}=0$ and $\mathrm{OPTT}=0$, (b) $\mathrm{TF}_{\max }, \mathrm{TW}_{4}$, $\mathrm{TT}_{\max }$ and $\mathrm{X}_{\mathrm{cc}}$, with respect to $\triangle \mathrm{OA}$ for $\alpha=1, \Delta \mathrm{HA}=1$ and $\mathrm{OPTT}=0$ \{Normalized values shown and $\mathrm{D}$ is the desirability function\}. 


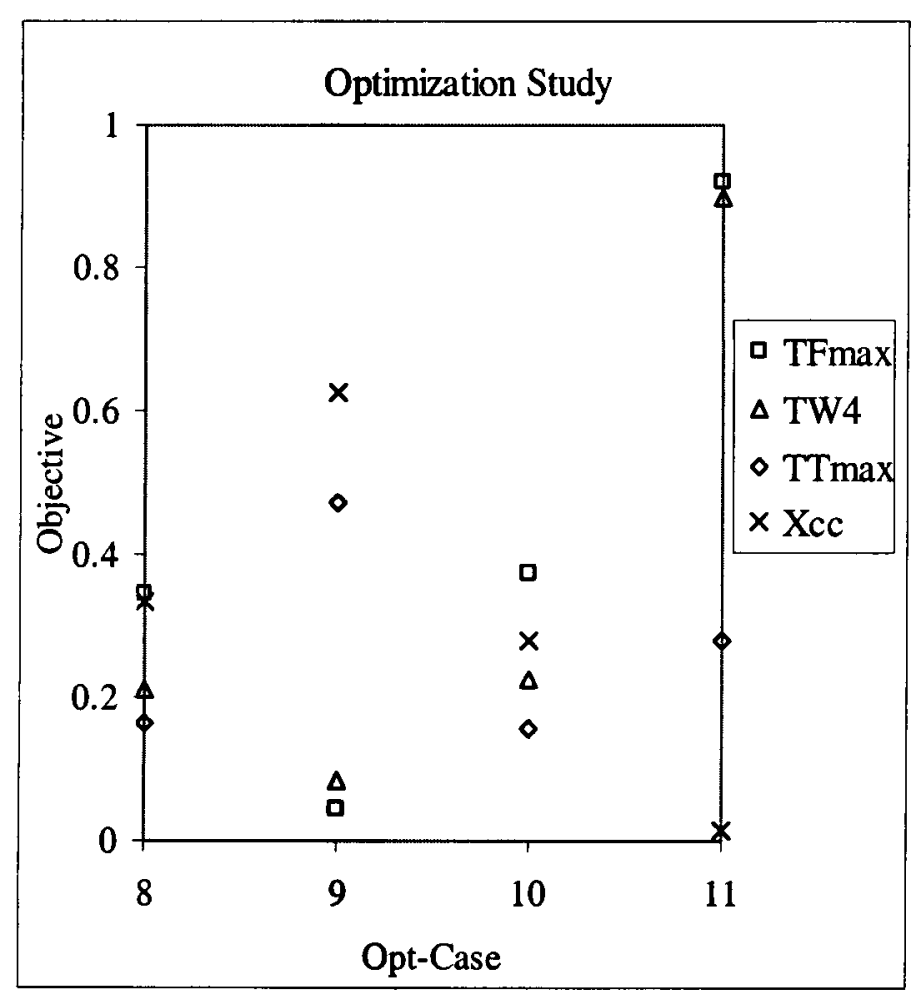

(a)

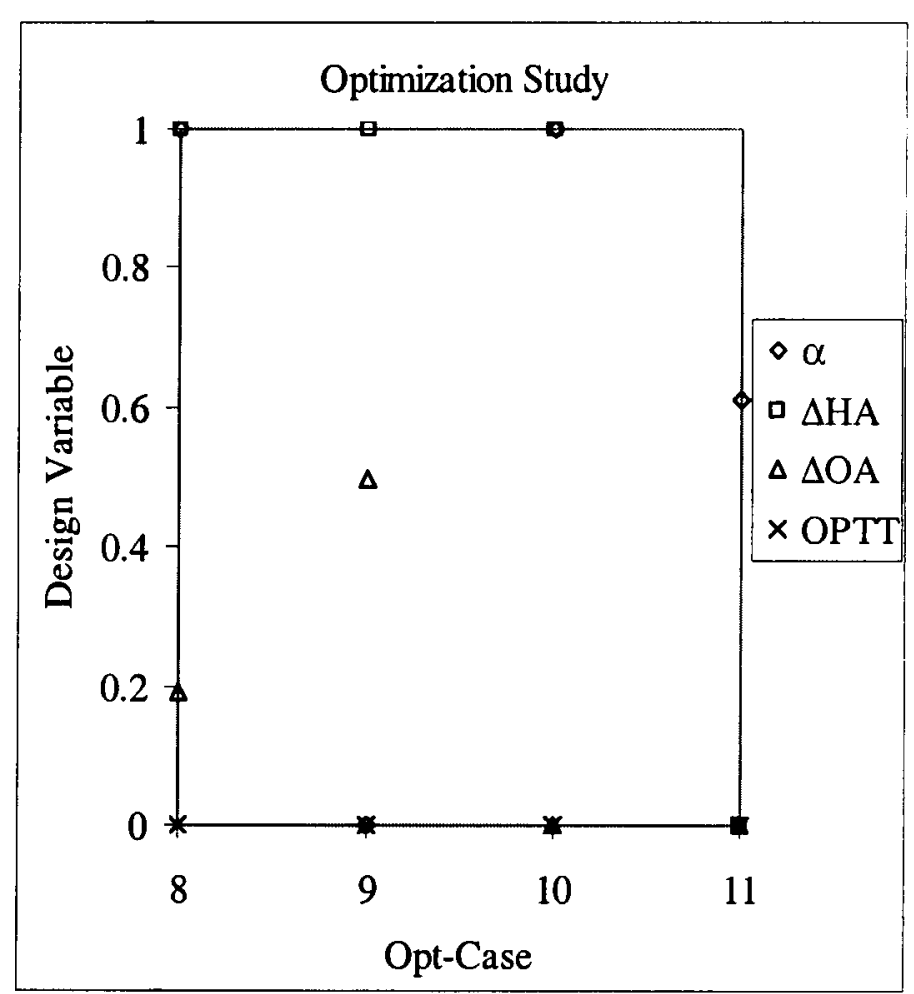

(b)

Figure 15: Composite minimization of objectives with different weightings.(Case $8:(1,1,1,0.5)$, Case $9:(5,5,5,0.1)$, Case 10: $(0.5,0.5,0.5,1)$, Case 11: $(0.1,0.1,0.1,5))$ \{The values in parenthesis indicates weights for $\left.\left(\mathrm{TF}_{\max }, \mathrm{TW}_{4}, \mathrm{TT}_{\max }, \mathrm{X}_{\mathrm{cc}}\right)\right\}$, (a) Objectives, (b) Design Variables \{Normalized values shown\}.

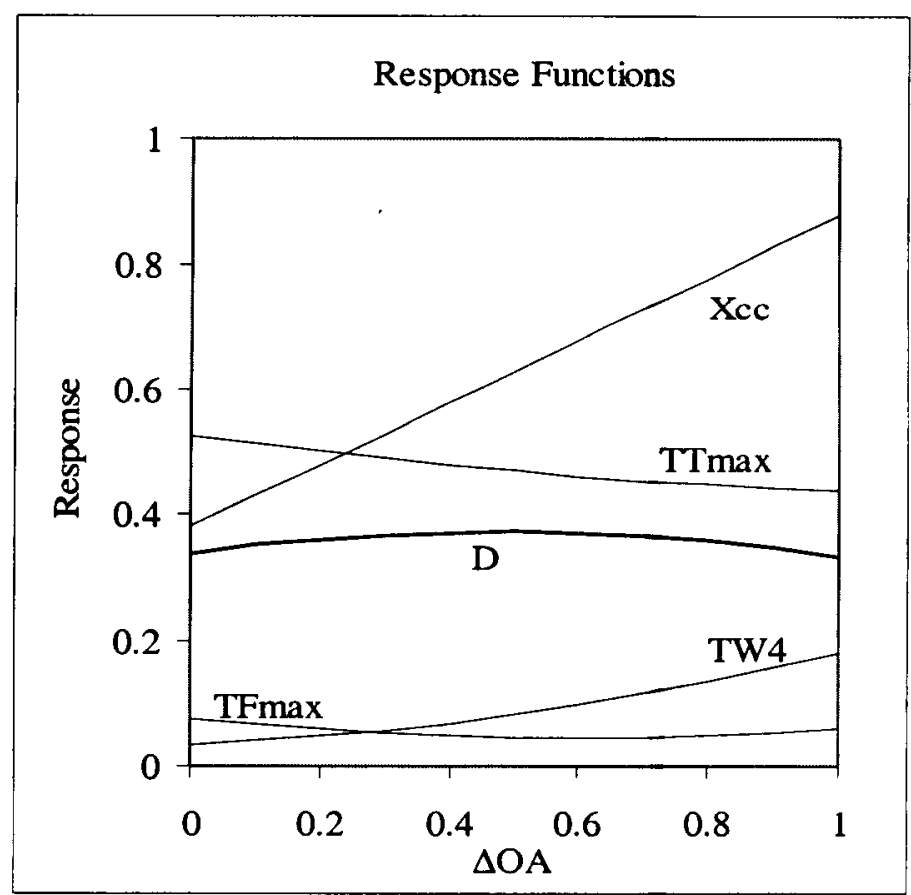

Figure 16: Variation of $\mathrm{TF}_{\max }, \mathrm{TW}_{4}, \mathrm{TT}_{\max }$ and $\mathrm{X}_{\mathrm{cc}}$, with respect to $\triangle \mathrm{OA}$ for $\alpha=0, \Delta \mathrm{HA}=1$ and OPTT $=0$ (Normalized values shown and $\mathrm{D}$ is the desirability function\}. 
APPENDIX

\begin{tabular}{|c|c|c|c|c|}
\hline & $\mathrm{H}_{2}$ flow angle ( $\left.\propto\right)$ & $\begin{array}{c}\text { Change in } \mathrm{H}_{2} \text { flow } \\
\text { Area }(\triangle \mathrm{HA})\end{array}$ & $\begin{array}{c}\text { Change in } \mathrm{O}_{2} \text { flow } \\
\text { Area }(\Delta \mathrm{OA})\end{array}$ & $\begin{array}{c}\mathrm{O}_{2} \text { post tip thickness } \\
\text { (OPTT) }\end{array}$ \\
\hline Case 1: & 0 & 0 & 1 & 0 \\
\hline Case 2: & 0 & 0 & 1 & 0.5 \\
\hline Case 3: & 0 & 0 & 1 & 1 \\
\hline Case 4: & 0.5 & 0.5 & 0 & 1 \\
\hline Case 5: & 1 & 1 & 0.5 & 0 \\
\hline Case 6: & 1 & 1 & 0.5 & 0.5 \\
\hline Case 7: & 1 & 1 & 0.5 & 1 \\
\hline Case 8: & 0 & 0.5 & 0.5 & 0 \\
\hline Case 9: & 0.5 & 1 & 1 & 0 \\
\hline Case 10: & 0.5 & 1 & 1 & 0.5 \\
\hline Case 11: & 0.5 & 1 & 1 & 1 \\
\hline Case 12: & 1 & 0 & 0 & 0 \\
\hline Case 13: & 1 & 0 & 0 & 0.5 \\
\hline Case 14: & 1 & 0 & 0 & 1 \\
\hline Case 15: & 0 & 1 & 0 & 0 \\
\hline Case 16: & 0 & 1 & 0 & 0.5 \\
\hline Case 18: & 0.5 & 0 & 0.5 & 0 \\
\hline Case 19: & 0.5 & 0 & 0.5 & 1 \\
\hline Case 20: & 1 & 0.5 & 1 & 0 \\
\hline Case 21: & 1 & 0.5 & 1 & 0.5 \\
\hline Case 22: & 1 & 0.5 & 1 & 1 \\
\hline Case 23: & 0 & 1 & 0.5 & 0 \\
\hline Case 24: & 0 & 1 & 0.5 & 1 \\
\hline Case 25: & 0.5 & 0 & 1 & 0 \\
\hline Case 26: & 0.5 & 0 & 1 & 1 \\
\hline Case 27: & 1 & 0.5 & 0 & 0 \\
\hline Case 28: & 1 & 0.5 & 0 & 1 \\
\hline Case 29: & 0 & 0 & 0 & 0 \\
\hline Case 30: & 0 & 0 & 0 & 0.5 \\
\hline Case 32: & 0.5 & 0.5 & 0.5 & 0.5 \\
\hline Case 33: & 1 & 1 & 1 & 0 \\
\hline Case 34: & 1 & 1 & 1 & 1 \\
\hline Case 35: & 0 & 0.5 & 1 & 0 \\
\hline Case 36: & 0 & 0.5 & 1 & 1 \\
\hline Case 37: & 0.5 & 1 & 0 & 0 \\
\hline Case 38: & 0.5 & 1 & 0 & 1 \\
\hline Case 39: & 1 & 0 & 0.5 & 0 \\
\hline Case 40: & 1 & 0 & 0.5 & 1 \\
\hline
\end{tabular}

Table Ala: Training data (missing Case numbers indicate the unacceptable Cases). 
$\therefore \because$

\begin{tabular}{|c|c|c|c|c|}
\hline & $\alpha$ & $\Delta \mathbf{H A}$ & $\Delta \mathbf{O A}$ & OPTT \\
\hline Case 41: & 0.5 & 0.5 & 0 & 0 \\
\hline Case 42: & 0.5 & 0.5 & 0 & 0.5 \\
\hline Case 43: & 0 & 0.5 & 0.5 & 0.5 \\
\hline Case 44: & 0 & 0.5 & 0.5 & 0.5 \\
\hline Case 45: & 0.5 & 0 & 0.5 & 0.5 \\
\hline Case 46: & 0 & 1 & 0.5 & 0.5 \\
\hline Case 47: & 0.5 & 0 & 1 & 0.5 \\
\hline Case 48: & 1 & 0.5 & 0 & 0 \\
\hline Case 49: & 0.5 & 0.5 & 0.5 & 1 \\
\hline Case 50: & 0.5 & 0.5 & 0.5 & 0.5 \\
\hline Case 51: & 1 & 1 & 1 & 0.5 \\
\hline Case 52: & 0 & 0.5 & 1 & 0.5 \\
\hline Case 53: & 0.5 & 1 & 0 & 0.5 \\
\hline Case 54: & 1 & 0 & 0.5 & \\
\hline
\end{tabular}

Table Alb: Testing data.

$\mathrm{TF}_{\max }=0.692+0.477(\alpha)-0.687(\Delta \mathrm{HA})-0.080(\Delta \mathrm{OA})-0.0650(\mathrm{OPTT})-0.167(\alpha)^{2}-0.0129(\Delta \mathrm{HA})(\alpha)+0.0796(\Delta \mathrm{HA})^{2}-$ $0.0634(\Delta \mathrm{OA})(\alpha)-0.0257(\Delta \mathrm{OA})(\Delta \mathrm{HA})+0.0877(\Delta \mathrm{OA})^{2}-0.0521(\mathrm{OPTT})(\alpha)+0.00156(\mathrm{OPTT})(\Delta \mathrm{HA})+$ $0.00198(\mathrm{OPTT})(\triangle \mathrm{OA})+0.0184(\mathrm{OPTT})^{2}$. (A1)

$\mathrm{TW}_{4}=0.758+0.358(\alpha)-0.807(\Delta \mathrm{HA})+0.0925(\Delta \mathrm{OA})-0.0468(\mathrm{OPTT})-0.172(\alpha)^{2}+0.0106(\Delta \mathrm{HA})(\alpha)+0.0697(\Delta \mathrm{HA})^{2}-$ $0.146(\Delta \mathrm{OA})(\alpha)-0.0416(\Delta \mathrm{OA})(\Delta \mathrm{HA})+0.102(\Delta \mathrm{OA})^{2}-0.0694(\mathrm{OPTT})(\alpha)-0.00503(\mathrm{OPTT})(\Delta \mathrm{HA})+$ $0.0151(\mathrm{OPTT})(\Delta \mathrm{OA})+0.0173(\mathrm{OPTT})^{2}$.

(A2)

$\mathrm{TT}_{\max }=0.370-0.205(\alpha)+0.0307(\Delta \mathrm{HA})+0.108(\Delta \mathrm{OA})+1.019(\mathrm{OPTT})-0.135(\alpha)^{2}+0.0141(\Delta \mathrm{HA})(\alpha)+0.0998(\Delta \mathrm{HA})^{2}+$ $0.208(\Delta \mathrm{OA})(\alpha)-0.0301(\Delta \mathrm{OA})(\Delta \mathrm{HA})-0.226(\Delta \mathrm{OA})^{2}+0.353(\mathrm{OPTT})(\alpha)-0.0497(\mathrm{OPTT})(\Delta \mathrm{OA})-0.423(\mathrm{OPTT})^{2}+$ $0.202(\Delta \mathrm{HA})(\alpha)^{2}-0.281(\Delta \mathrm{OA})(\alpha)^{2}-0.342(\Delta \mathrm{HA})^{2}(\alpha)-0.245(\Delta \mathrm{HA})^{2}(\Delta \mathrm{OA})+0.281(\Delta \mathrm{OA})^{2}(\Delta \mathrm{HA})-0.184(\mathrm{OPTT})^{2}(\alpha)-$ $0.281(\Delta \mathrm{HA})(\alpha)(\Delta \mathrm{OA})$

(A3)

$\mathrm{X}_{\mathrm{cc}}=0.153-0.322(\alpha)+0.396(\Delta \mathrm{HA})+0.424(\Delta \mathrm{OA})+0.0226(\mathrm{OPTT})+0.175(\alpha)^{2}+0.0185(\Delta \mathrm{HA})(\alpha)-0.0701(\Delta \mathrm{HA})^{2}-$ $0.251(\Delta \mathrm{OA})(\alpha)+0.179(\Delta \mathrm{OA})(\Delta \mathrm{HA})+0.0150(\Delta \mathrm{OA})^{2}+0.0134(\mathrm{OPTT})(\alpha)+0.0296(\mathrm{OPTT})(\Delta \mathrm{HA})+0.0752(\mathrm{OPTT})(\Delta \mathrm{OA})$ +0.0192 (OPTT) ${ }^{2}$. (A4) 